\title{
Lignin-Based Composite Materials for Photocatalysis and Photovoltaics
}

\author{
Ayesha Khan $^{1} \cdot$ Vaishakh Nair $^{1} \cdot J_{\text {Juan Carlos Colmenares }}{ }^{1} \mathbb{D} \cdot$ Roger Gläser $^{2}$
}

Received: 14 February 2018 / Accepted: 19 April 2018 / Published online: 2 May 2018 (C) The Author(s) 2018

\begin{abstract}
Depleting conventional fuel reserves has prompted the demand for the exploration of renewable resources. Biomass is a widely available renewable resource that can be valorized to produce fuels, chemicals, and materials. Among all the fractions of biomass, lignin has been underutilized. Due to its complex structure, recalcitrant nature, and heterogeneity, its valorization is relatively challenging. This review focuses on the utilization of lignin for the preparation of composite materials and their application in the field of photocatalysis and photovoltaics. Lignin can be used as a photocatalyst support for its potential application in photodegradation of contaminants. The interaction between the components in hybrid photocatalysts plays a significant role in determining the photocatalytic performance. The application of lignin as a photocatalyst support tends to control the size of the particles and allows uniform distribution of the particles that influence the characteristics of the photocatalyst. Lignin as a semiconductive polymer dopant for photoanodes in photovoltaic cells can improve the photoconversion efficiency of the cell. Recent success in the development of lignosulfonates dopant for hole transport materials
\end{abstract}

Chapter 1 was originally published as Khan, A., Nair, V., Colmenares, J. C. \& Gläser, R. Topics in Current Chemistry (Z) (2018) 376: 20. https://doi.org/10.1007/s41061-018-0198-Z.

Ayesha Khan

akhan@ichf.edu.pl

$\bowtie$ Juan Carlos Colmenares

jcarloscolmenares@ichf.edu.pl

$\triangle$ Roger Gläser

roger.glaeser@uni-leipzig.de

1 Institute of Physical Chemistry, Polish Academy of Sciences, Kasprzaka 44/52, 01-224 Warsaw, Poland

2 Institute of Chemical Technology, Leipzig University, Linnéstr. 3, 04103 Leipzig, Germany 
in photovoltaics will pave the way for further research in lignin-based high-performance organic electronic devices.

Keywords Lignin - Composite materials · Photocatalysis · Photodegradation · Photovoltaics $\cdot$ Photoactive materials

\section{Abbreviations}

UV

$T_{\mathrm{g}}$

$T_{\mathrm{d}}$

$\mathrm{RhB}$

ITO

HOMO

LUMO

PEDOT:PSS

P3HT

PCBM

LA

MO

$\mathrm{AL}$

LPQAS

SLS

PFI

HIL

SL

ASL

PCE

GSL

$\mathrm{G}$

$\mathrm{S}$

$\mathrm{H}$

SAF

MWNTs

AL

HTL

HTM

HEL

$\mathrm{PC}_{71} \mathrm{BM}$

PTB7

Th

$\mathrm{J}_{\mathrm{SC}}$

$V_{\mathrm{OC}}$

FF
Ultraviolet

Glass transition temperature

Degradation temperature

Rhodamine B

Indium-tin-oxide

Highest occupied molecular orbital

Lowest unoccupied molecular orbital

Poly(3,4-ethylenedioxythiophene): poly(styrene sulfonate)

Poly(3-hexylthiophene)

[6]-Phenyl-C61-butyric acid methyl ester

Lignin-amine

Methyl orange

Aminated lignin

Lignin-phosphate quaternary ammonium salt

Sodium lignosulphonates

Perfluorinated ionomer

Hole injection layer

Lignosulfonate

Alkyl chain cross-linked lignosulfonate

Photoconversion efficiency

Grafted sulfonated acetone-formaldehyde lignin

Guaiacyl

Syringyl

p-Hydroxybenzaldehyde

Sulfonated acetone-formaldehyde

Multi-walled carbon nanotubes

Alkali lignin

Hole transport layer

Hole transport material

Hole extracting layer

[6,6]-Phenyl- $\mathrm{C}_{71}$-butyric acid methyl ester

Poly[[4,8-bis[(2-ethylhexyl)oxy]benzo[1,2-b:4,5- $\left.b^{\prime}\right]$

dithiophene-2,6-diyl][3-fluoro-2-[(2-ethylhexyl)carbonyl]

thieno[3,4- $b$ ]thiophenediyl]]

Benzodithiophene

Short-circuit current density

Open-circuit voltage

Fill factor 


$\begin{array}{ll}\text { PFN } & \begin{array}{l}\text { Poly[ }(9,9-\text {-bis( } 3 \text { '-(N,N-dimethylamino) } \\ \text { propyl)-2,7-fluorene)-alt-2,7-(9,9-dioctylfluorene })]\end{array} \\ \text { [Ir(ppy)2(dtbbpy)]PF66 } & 4,4 \text { '-Di-tert-butyl-2,2'-bipyridine)bis[(2-pyridinyl)phenyl] } \\ & \text { iridium(III) hexafluorophosphate }\end{array}$

\section{Introduction}

The chemical industry principally depends on fossil resources for the manufacturing of carbon-based compounds. However, dwindling supply of conventional fuels and the search for alternative raw materials for chemical production has made biomass an attractive resource that has significant potential for the production of chemicals, fuels, and materials, paving the way for a sustainable future [1]. Lignin is a major fraction of biomass besides cellulose and hemicellulose that accounts for $40 \%$ of the total lignocellulosic biomass energy. However, little attention has been paid to the valorization of lignin due to its complex nature [2]. Recently, works have been reported for the conversion of lignin into value-added chemicals like aromatics [3], low molecular weight hydrocarbons, and fuel [4] through depolymerization reactions and gasification, respectively.

The term "lignin" is devised from the Latin word "lignum", which means wood [5]. Lignin accounts for about 15-30\% of the total biomass content in plants, annually about 150 billion tons of lignin is produced by plants, which make it the most abundantly available natural polymer next to cellulose. It stores about $0.082 \%$ (3000 EJ year ${ }^{-1}$ ) of all the solar radiation intercepted the earth surface, which accounts for approximately 5.4 times the present global energy consumption rate. With the empirical formula of $\mathrm{C}_{31} \mathrm{H}_{34} \mathrm{O}_{11}$, lignin contains about 95 billion tons of the carbon in the earth crust, which illustrates the unexploited high carbon energy reserve [6].

Lignin has an extensively branched three-dimensional chemical structure with various functional moieties such as carboxyl $(\mathrm{COOH})$, carbonyl $(\mathrm{C}=\mathrm{O})$, and methoxy $\left(\mathrm{CH}_{3} \mathrm{O}\right)$, respectively. It is a macromolecule made up of repeating phenyl propane-based monolignols subunits, which are coniferyl alcohol (G), sinapyl alcohol $(\mathrm{S})$, and low amounts of $p$-coumaryl alcohol $(\mathrm{H})$ that take part in lignin formation (Fig. 1). Common linkages found in heterogeneous, high molecular weight lignin are $\beta-\mathrm{O}-4, \alpha-\mathrm{O}-4, \beta-5, \beta-\beta, 5-5^{\prime}, 4-\mathrm{O}-5, \beta-1^{\prime}$ [7]. The percentage content of monolignol subunits varies among different plant species. Similar to the monomers content, there is also a variation in the percentage of linkages with respect to plant species [8]. The variation in linkages and monolignols content with plant species make the actual structure determination of lignin rather difficult [9].

Among all the fractions of biomass, lignin has been comparatively underutilized attributed to its complex structure, recalcitrant nature, and heterogeneity that make its valorization relatively challenging. Lignin comprises $30 \%$ of all the organic carbon stockpiled in the biosphere [10,11]. Moreover, the pulp and paper as well as the bioethanol industry produce copious amounts of lignin as a side product that is mainly exploited for power and heat generation via combustion. Out of 50 million tons of lignin produced by the pulp and paper industry in 2010 , only $2 \%$ has been 
(a)

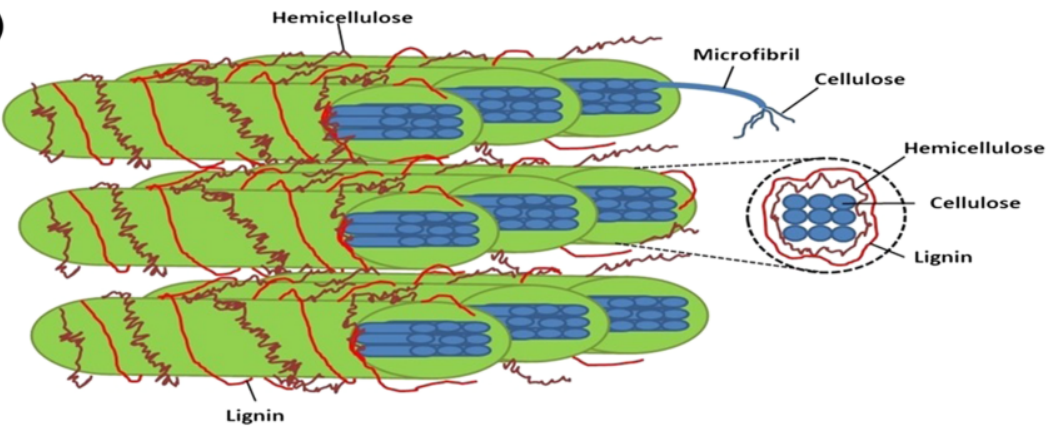

(b)

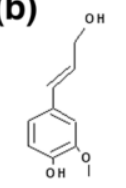

Coniferyl Alcohol

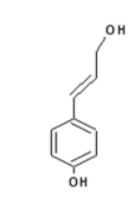

p- coumaryl Alcohol

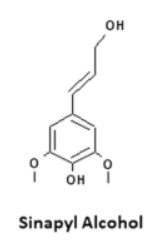

(c)

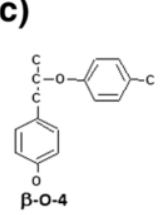

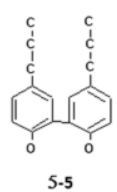

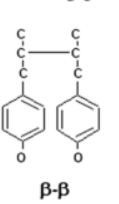

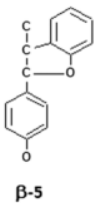

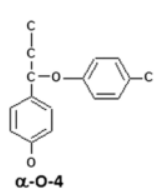

$\beta-5$

Fig. 1 a Plant cell wall structure and microfibril cross section (strands of cellulose molecules embedded in a matrix of hemicellulose and lignin) [12]. b Monolignols units in lignin [12]. c Common linkages found in lignin [13]

utilized for the production of chemicals, while a high fraction is just burned as lowquality fuel [9]. However, the high aromaticity of lignin makes it a potential precursor for the production of a number of chemicals. In the context of sustainability and economic viability, lignin valorization may play a key role. Therefore, there is a need to concentrate on developing efficient, cost-effective, and green methods for the valorization of lignin [11].

Along with the generation of value-added chemicals, application of lignin for manufacturing of high-performance materials with tunable structure and properties such as high-value polymeric materials or supercapacitors to adsorbents and from biomedical application to electrode materials $[14,15]$ is progressively becoming a focus of current research [9]. In 2014, the overall lignin market around the globe was valued at approximately US\$775 million, and it is anticipated that in 2020 it will reach approximately US $\$ 900$ million, consistent with an annual average growth rate of $2.5 \%$ within 2015 and 2020 [16]. A moderately slow growth rate originated from the impediments in handling of lignin due to its complex nature as well as from the isolation methods employed that utilizes lignin as a fuel [17].

The basic aim of this review is to summarize the recent progress in lignin-based materials for their application in heterogeneous photocatalysis (2013-2017) and photovoltaics (2015-2016). Photocatalysis and photovoltaics are the two major routes for the exploitation of solar energy. Moreover, photocatalysis is a key route, 
specifically for the degradation of contaminants in water. Recently, some ligninbased composites have shown high activity for the photocatalytic environmental remediation processes such as desulphurization and degradation of organic dyes [18-20]. Organic photovoltaic cells have gained much attention over the last few decades due to their potential application in reducing energy and environmental impact caused by the increasing combustion of fossil fuels. Substantial efforts have been made towards understanding the mechanism of photovoltaic cells together with modifying chemical structural motifs and device structure leading to the enhancement of power conversion efficiency from $4 \%$ to over $25 \%$ using silicon. Although the energy conversion efficiency of the conventional materials like crystalline $\mathrm{Si}$ is high (25\%), these materials also have high manufacturing and installation costs [21]. Another critical aspect in photovoltaic devices is the anode interface, where hole extraction and hole injection takes place; a hole conducting polymer is required for this function. PEDOT:PSS is most commonly used conducting polymer applied in anode interfaces. However, it has several drawbacks such as its acidic nature that induces corrosion and variable conductivities due to its microstructural and electrical inhomogeneity. Lignosulphonates have recently been introduced as dopant with tunable conductivities and work function to modify the anode interface [22]. Application of lignin in the field of photovoltaics for the development of organic electronic devices is a sustainable approach towards electricity generation. Nevertheless, several articles have been published on carbon-based hybrid materials for photocatalysis, specifically on the degradation of organic contaminants in water [23], but insufficient information is available on the synthesis of lignin-based composite materials and their limitations and applications in the field of photocatalysis and photovoltaics.

\section{Native Versus Processed Lignin}

\subsection{Sources}

Lignocellulosic biomass is the natural source of lignin. Both woody and non-woody biomass resources contain significant amounts of lignin [24]. Lignin along with cellulose and hemicellulose is a principal constituent of a plant's cell wall. The key function of lignin in the cell wall is to provide rigidity by reinforcing strength of crystalline cellulose and middle lamella that enable the erect growth of plants [9]. The content of lignin varies considerably among different plant species, and typically decreases from softwood to hardwood to grasses [24]. Furthermore, approximately 50 million tons of lignin is produced annually by chemical processing of pulp in bioethanol refineries and paper industry $[17,25]$.

\subsection{Classification of Lignin}

Lignin is categorized into the following three major classes based on its origin [24] 
- Guaiacyl lignin contains significantly high concentrations of coniferyl alcohol with the G:S:H ratio of 90:2:8. It is also named softwood lignin, mainly derived from coniferous trees.

- Guaiacyl-syringyl lignin contains significant amounts of sinapyl alcohol in addition to coniferyl alcohol. It is also known as hardwood lignin, principally found in deciduous trees and shrubs.

- Guaiacyl syringyl $p$-hydroxybenzaldehyde lignin contains a significant proportion of $p$-hydroxybenzaldehyde, approximately $30 \%$ in combination with other phenyl propane subunits. Lignin derived from monocotyledons falls into this category.

\subsection{Extraction of Lignin}

The isolation of lignin from lignocellulosic biomass is carried out under different conditions where polymeric lignin is chemically degraded to low molecular weight fragments, with different physicochemical properties. In addition to the source, composition and properties of the isolated lignin vary depending on the method of extraction. Generally, acid- or base-catalyzed reactions are commonly used in the extraction and depolymerization of lignin [24]. At an industrial scale, four methods are generally employed for lignin extraction that can be further categorized into two classes based on the presence of sulfur. Sulphur-containing lignin is extracted through the sulfite and Kraft processes. On the other hand, soda and organosolv processes are applied for the isolation of non-sulphur-containing lignin [9].

\subsubsection{Sulfite Process}

Sulfite-pulping process is a commonly used method for the production of commercial lignin. Different concentrations of sulfite or bisulfite salts of ammonium, magnesium, sodium, or calcium are used in an aqueous solution within the $\mathrm{pH}$ range of 1-13.5 [26]. The reaction temperature is usually maintained between 140 and $160{ }^{\circ} \mathrm{C}$ [27]. Delignification in sulfite pulping process involves the sulfonation of the aliphatic chain of the lignin via cleavage of $\alpha$-O-4-ether. The lignosulfonates produced through the sulfite process are water soluble and easily dissolved in pulping liquor in an aqueous media [9].

\subsubsection{Soda Process}

The first pulping process applied for the isolation of lignin was the soda process, introduced by Watt and Burgess in 1854 [28]. The soda process involves heating of the biomass in an alkaline aqueous solution (sodium hydroxide solution) at a temperature of around $160{ }^{\circ} \mathrm{C}$ [9]. The reaction proceeds with the protonation of phenolic hydroxyl moieties of lignin with simultaneous cleavage of $\alpha-\mathrm{O}-4$ and $\beta-\mathrm{O}-4$ bonds [17]. The lignin produced through the soda process is soluble in water and upon acidification it is isolated from pulp liquor through precipitation reaction [9]. 


\subsubsection{Kraft Process}

The most commonly used method for pulping is the Kraft process, which produces sulphur-containing lignin. Large fractions (98\%) of lignin produced through the Kraft process are utilized for energy purposes through combustion, and merely minor fractions (2\%) are used for material or chemical synthesis [9, 17]. The Kraft process is supposed to be an advancement or progression of the soda process, as it involves the heating of pulping liquor with sodium sulfide in addition to sodium hydroxide at a temperature between 150 and $180{ }^{\circ} \mathrm{C}[9$, 26]. The process of lignin depolymerization in the Kraft process is the same as in the soda process; the reaction proceed with the cleavage of $\alpha-\mathrm{O}-4$ and $\beta-\mathrm{O}-4$ ether linkages and results in soluble fragments of lignin [17]. A minor fraction of resultant lignin is sulphated due to the presence of anions of hydrosulfide. A large fraction of lignin produced is sulphate-free and isolated via acidification and precipitation method [9, 29].

\subsubsection{Organosolv Process}

The most recent process used for the extraction of lignin at an industrial scale is the organosolv process. This technique involves heating the biomass with a mixture of organic solvents for isolating lignin. Polar organic solvents such as methanol, acetone, ethanol, acetic acid, and formic acid are commonly used for the extraction process $[9,17]$. The nature of the solvent used significantly determines the structure and properties of the isolated lignin [9].

\subsection{Properties of Lignin}

Native lignin is colorless, but acid-alkali treatment changes its color to dark brown [5]. Physical and chemical properties of the lignin vary with the extraction procedure and the monolignols content [9], as shown in Table 1. The functional moieties of lignin like carboxylic, phenolic hydroxyls, methoxy, aliphatic and carbonyl groups depend on the monomeric linkages. Moreover, these moieties significantly contribute to the chemical modification of lignin [9]. The molecular weight of lignin ranges between 1000 and 20,000 $\mathrm{g} \mathrm{mol}^{-1}$. As lignin constantly degrades during the extraction process, it is therefore difficult to predict the degree of polymerization attributed to random repetition of subunits [25].

The glass transition temperature $\left(T_{\mathrm{g}}\right)$ of lignin differs with moisture content, molecular weight, extraction method, cross-link density, and measurement method. $T_{\mathrm{g}}$ generally increases with the increase in molecular weight, based on the structure and fragments' molecular mass the $T_{\mathrm{g}}$ of lignin falls between 70 and $170{ }^{\circ} \mathrm{C}$ [30]. Analogous discrepancies have been observed for the decomposition temperature of lignin, lignin source, extraction method, and measurement techniques influence lignin decomposition processes [31]. Distinct decomposition 


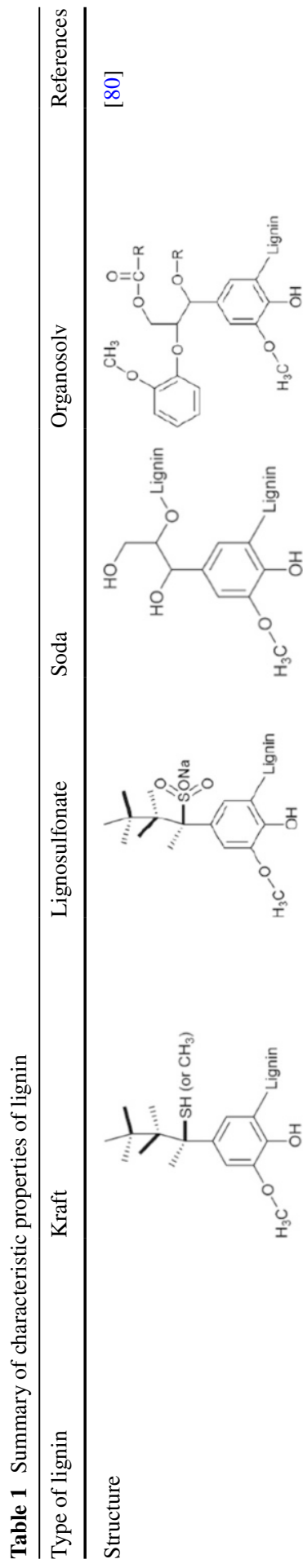

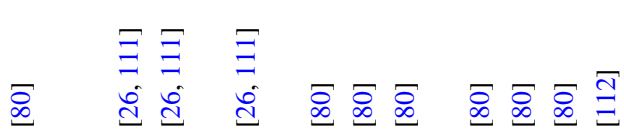
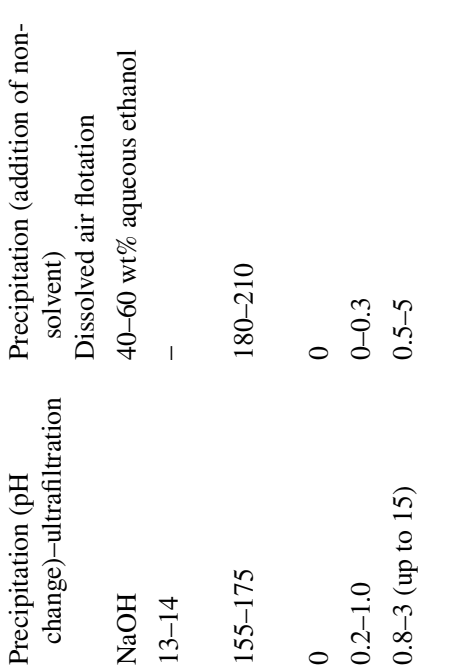

苞

宊

4

on

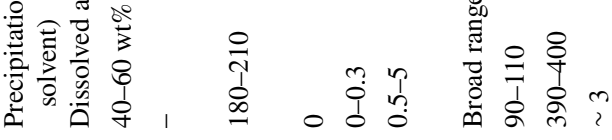

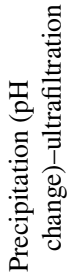

造紊

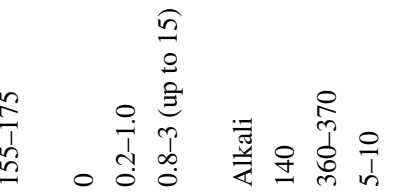

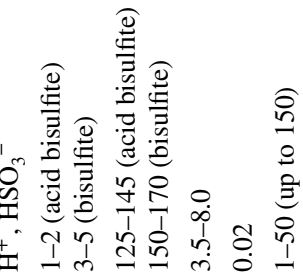

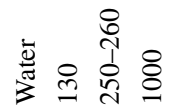

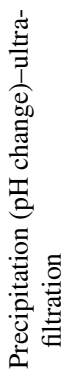

$\frac{0}{\overline{0}}$

莙

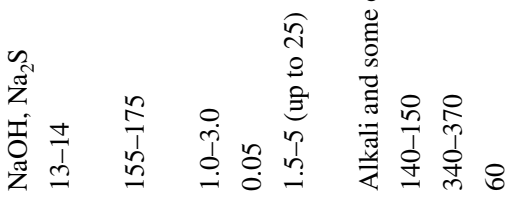

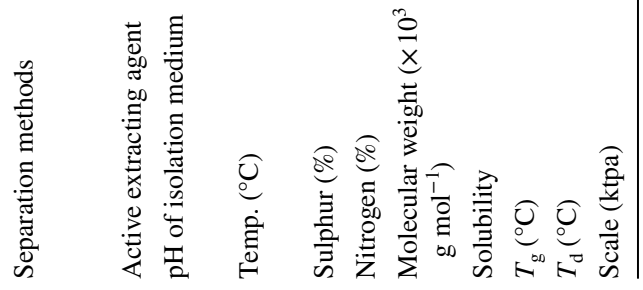


of lignin comparable to other biomass components have been observed in the range of $360-480{ }^{\circ} \mathrm{C}$ via thermogravimetry [32].

Furthermore, lignin has many valuable properties such as antimicrobial and antioxidant nature [33], mechano-thermal stability [34], and blending properties [5] that make it a potential candidate as a constituent of composites. In addition to its benefits, it has some limitations, such as abrupt changes in its properties with change in moisture content. Bleaching of produced radicals and reaction with atmospheric oxygen is the major drawback of lignin for its application in material synthesis [35]. These limitations may be overcome by chemical modification introduction of lignin into composite materials [36].

\section{General Applications of Lignin}

\subsection{Synthesis of Materials from Lignin}

Depletion of fossil resources and associated environmental problems has resulted in exploration of renewable resources for the synthesis of materials. Lignin as a renewable biopolymer has a big role to play in this field due its natural abundance. Lignin is a potential candidate for the fabrication of composite materials credited to it several remarkable features such as biodegradability, antioxidant activity, antimicrobial activity, and reinforcing properties etc. [37]. Recently composites based on lignin gained a lot of attention due to its property to be used as a reinforcing material for the synthesis of high-performance composites. Morandim-Giannetti et al. investigated the application of lignin as additive for the fabrication of polypropylene-coir composites [38]. The tensile strength of the composite has not been affected to a large extent by the addition of lignin, though initial degradation temperature and oxidation induction time of the composite has been increased due to the presence of lignin. Moreover, the multifunctional nature of lignin makes it a reactive component for the manufacturing of resins and polymer-based materials. This goal is achieved either through chemical modification of lignin through esterification, phenolation and oxypropylation reaction, or through partial substitution of traditional materials by lignin. Similarly, lignin has shown promising application for the preparation of phenol-formaldehyde resins, epoxy resins, polyurethanes, and graft copolymers [17].

Lignosulfonate and kraft lignin in combination with activated carbon have been used in direct carbon fuel cells for the production of electricity [39]. Lignosulfonate showed better performance than Kraft lignin in direct carbon fuel cells due to high hydrophilicity of lignosulfonate. High wettability of lignosulfonate also enhances electrochemical reactivity and electrical conductivity in fuel cells. Using lignosulfonate-activated carbon, the maximum power density reaches $25 \mathrm{~mW} \mathrm{~cm}{ }^{-2}$, while Kraft lignin-activated carbon shows a power density of $12 \mathrm{~mW} \mathrm{~cm}^{-2}$ [40]. Furthermore, a study reported the production of highly nanoporous carbon for supercapacitors application using low-cost renewable lignin as precursor [41]. The better control over the surface functional groups, pore structure, and electrical conductivity of lignin-based carbon materials enhances the electrocapacitive performance of 
electrode for supercapacitors [14]. However, there are certain challenges associated with the lignin for its use in energy storage devices such as low electrical conductivity that make the active sites of lignin electrochemically inaccessible. The other factor is the solubility of some types of lignin like lignosulfonates in an aqueous media that may result in degradation of the active material in an electrochemical device [42]. Designing hybrid capacitors using lignin in combination with metal oxides and conductive polymers is a futuristic approach to improve the electrode capacitance of supercapacitors.

\section{Overview of Carbon-Based Materials in Photocatalysis and Photovoltaics}

Recently, tremendous attention has been paid to the development of porous carbonbased materials derived from environmentally friendly renewable biomass resources [43]. Carbon-based materials derived from biomass such as wood, cellulose, lignin, hemicellulose, and biochar widely used as template for semiconductors in photocatalytic applications [44]. Introducing carbon-based materials as doping agent plays a significant role in the modification of photocatalyst by improving visible light responsive performance of the photocatalyst [45, 46]. During photocatalysis, the high surface area, electrical conductivity, and porosity of carbon materials may increase the adsorption and modify the mechanism of photochemical reaction. This synergistic effect induced by carbon materials enhances the photocatalytic degradation of environmental pollutants, photocatalytic production of $\mathrm{H}_{2}$, and photocurrent generation attributed to their high electroconductivity [47].

Various efforts have been made for the utilization of carbon-based materials like activated carbon and biochar for fabrication of composites. Activated carbon derived from biomass is considered to be a potential support for the photocatalytic material attributed to its ability to improve the interface charge transfer rate and reduce the electron hole recombination rate [48]. It has shown promising properties as support for $\mathrm{TiO}_{2}$ in case of gas and water remediation. Moreover, the heterojunction formed between the components leads to inoculation of electrons from activated carbon to $\mathrm{TiO}_{2}$ [49]. Similarly, $\mathrm{TiO}_{2}$ in combination with biochar (a porous solid-rich byproduct of thermal decomposition of organic waste) derived from Miscanthus straw pellets and soft wood pellets has shown enhanced photocatalytic activity for selective oxidation of methanol to methyl methanoate as well as for phenol degradation [50].

Among various biomass fractions, cellulose has been extensively utilized for the fabrication of hybrid photocatalyst [20, 51]. Composite films of $\mathrm{TiO}_{2}$ show high photocatalytic degradation efficiency for concentrated phenol accredited to the void formation in $\mathrm{TiO}_{2}$ assembly and their immobilization by hydroxyl groups [52]. Carbon-based photocatalyst composites with well-defined physicochemical characteristics such as specific surface area, pore volume, microstructure, and solubility etc., may enhance the photocatalytic system that ultimately pave the way to understand the reaction mechanism of the material synthesis based on its structure and composition [44]. Still, further investigation is required to understand the reaction 
kinetics and mechanism, interphase interaction, and leaching of components from composites.

Photovoltaics is another foremost mode for the utilization of solar energy for power generation. Due to high energy demand, there is a dire need to fabricate energy conversion devices utilizing renewable resource in accordance with the principles of green chemistry. About $1.8 \times 10^{11} \mathrm{MW}$ power is intercepted by the earth from the sun, which is quite greater than the current rate of overall energy consumption [53]. The field of photovoltaics offers great potential for the utilization of renewable solar power by converting it into electricity. Steady progress has been achieved in the field of photovoltaics in order to increase the power conversion efficiencies and lower the cost of production by using organic molecule or polymers in chemical design [54].

Photovoltaic technologies are required to be economically viable and environmentally friendly. The current photovoltaic devices are mostly centered on the use of toxic and expensive inorganic chemicals [55] such as CdTe, GaAs, $\mathrm{CuIn}_{x} \mathrm{Ga}_{1-x} \mathrm{Se}_{2}$ [56]. Semiconductors derived from organic polymer are potential alternative for inorganic semiconductive materials in the field of photovoltaics. Low cost, renewability, and conjugated structure are the most important features of organic polymers for their application in photovoltaics [57].

The importance of natural polymers for the fabrication of photovoltaic devices can be understood by the working principle of photovoltaics. A photovoltaic cell is composed of a layered structure in which the layer that absorbs light is packed between two different types of electrode, as depicted in Fig. 2. One of the electrodes is made up of indium-tin-oxide ITO, while the other electrode is often composed of metals like aluminum, calcium-magnesium, and gold, etc. Upon exposure to light, electrons residing in the highest occupied molecular orbital (HOMO) absorbing a certain wavelength of radiation and shifted to the lowest unoccupied molecular orbital (LUMO) result in the formation of exciton. Free electrons and holes generated through exciton dissociation move towards $\mathrm{Al}$ and ITO respectively, as depicted in Fig. 3. Movement of electrons in the external circuit generates an electric current. Asymmetrical electrodes' ionization energy or work functions provide an electric field required to avoid recombination. This asymmetry is responsible for the flow of electrons from the region of low work function to the region of high work function, the process is known as rectification. In case the semiconductors are based

Fig. 2 Basic construction of a photovoltaic cell with typical electrode materials. An organic material is sandwiched between two electrodes [57]

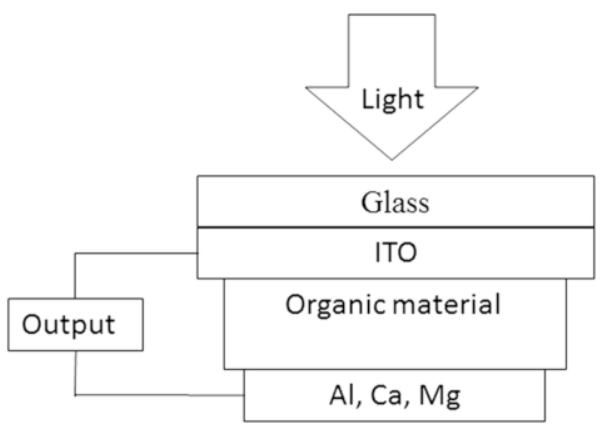


Fig. 3 Energy levels and light harvesting. Upon irradiation, an electron is promoted to the LUMO leaving a hole behind in the HOMO. Electrons are collected at the Al electrode and holes at the ITO electrode. $\Phi$, workfunction; $\chi$, electron affinity; IP, ionization potential; $E_{\mathrm{g}}$, optical band gap [57]

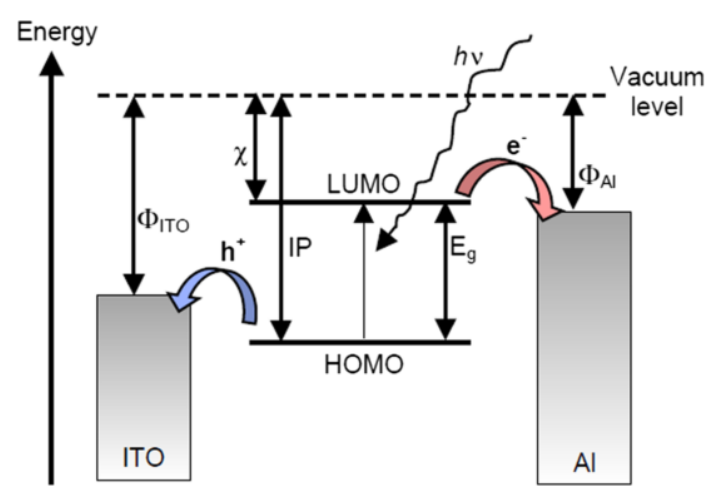

on inorganic materials, interaction of HOMOs and LUMOs of adjacent molecules result in a conduction and valence band. While in case of semiconductors based on organic dyes instead of bands, charge transfer takes place between localized states through hopping. Polymers have a conjugated structure placed in between organic dyes and inorganic semiconductors [57].

Nanocellulose has been used as substrate for the fabrication of photovoltaic and solar cells [58]. Carboxymethylated nanocellulose paper has been applied as a substrate in a device consisting of poly(3,4-ethylenedioxythiophene):poly(styrene sulfonate) (PEDOT:PSS), poly(3-hexylthiophene) (P3HT), and [6]-phenyl-C61-butyric acid methyl ester (PCBM). The photo conversion efficiency of the device was not very high $(0.2 \%)$, which was attributed to the high resistance of ITO [59].

The dye-sensitized solar cell is a type of photovoltaic cell that works on the principle of oxidation-reduction reaction with the capability of maximizing the power conversion efficiency up to $11 \%$ [60]. The microcrystalline cellulose applied as gel electrolyte for the dye-sensitized solar cell. The photovoltaic efficiency of dye-sensitized solar cell based on cellulose gel can be optimized by regulating cellulose concentration and ionic liquid volume ratio. The photoconversion efficiency reaches $3.33 \%$ by using a gel composed of LiI ( $2 \mathrm{wt} \%)$, iodine (10 wt $\%$ of the whole weight of iodide), microcellulose (5 wt $\%)$, 4-tert-butylpyridine (10 wt $\%)$, and 1-methyl3-propylimidazolium/1-ethyl-3-methylimidazolium thiocyanate (50/50 volume percentage) when stimulated more than $8 \mathrm{~h}$ under solar irradiation [61].

\subsection{Lignin-Based Composites in Photocatalysis}

\subsubsection{Preparation Techniques of Lignin-Based Composite Photocatalyst}

There are a number of methods employed for the synthesis of photocatalysts with lignin as a support (Table 2). Depositing or immobilizing a photoactive material on or within the pores of lignin-based supports might offer substantial gains in photocatalysis, especially if the photoactive component can be introduced in an oriented or assembled fashion. There are several methods used for the preparation of ligninbased photocatalyst such as solid-phase synthesis, solvent evaporation method, 


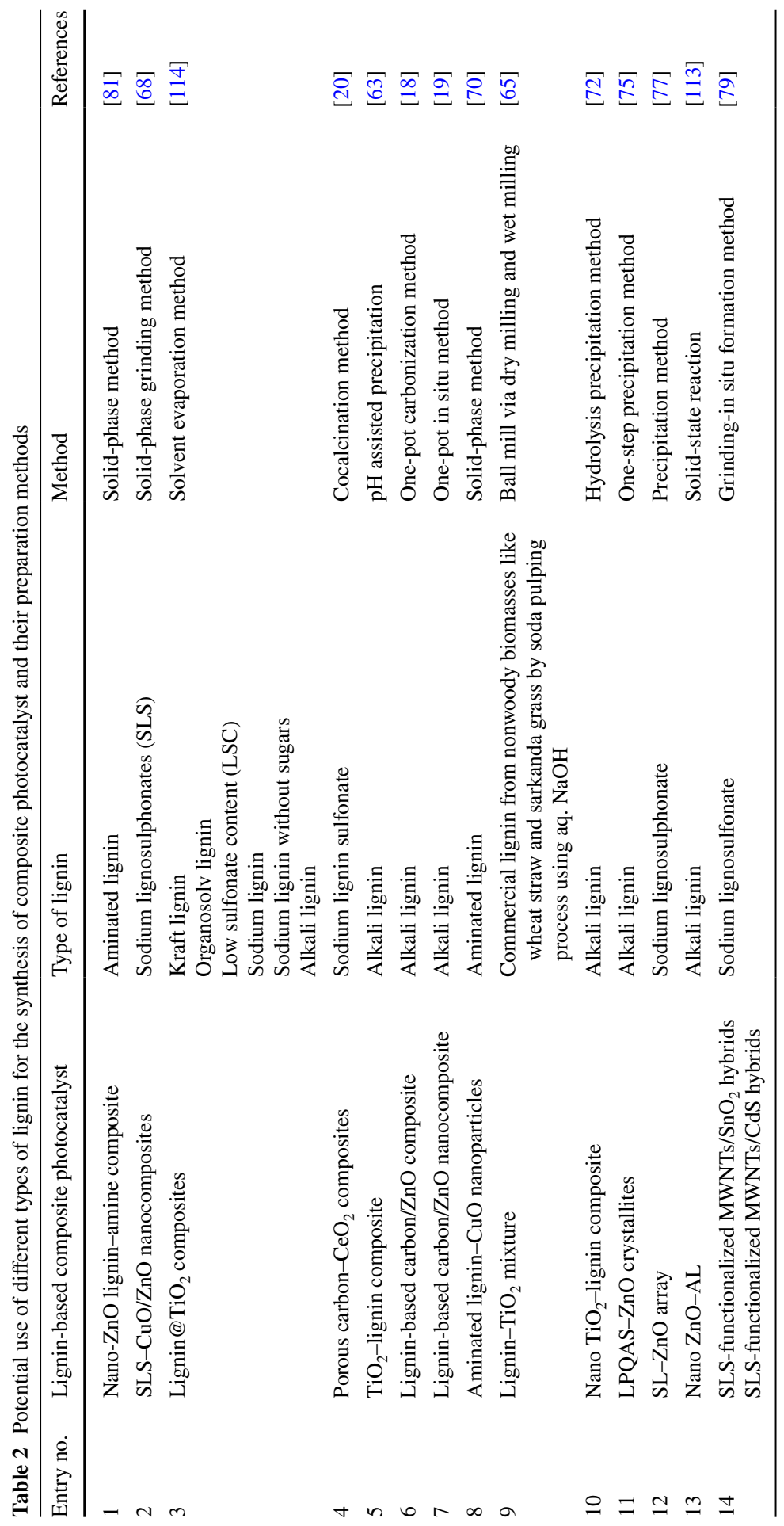


cocalcination, one-pot in situ method, and $\mathrm{pH}$-assisted precipitation (see Table 2 for details).

Precipitation is one of the most frequently applied and cost-efficient methods for the synthesis of photocatalyst composites. More than one layer of photoactive material can be deposited in a homogeneous distribution on the lignin-based support without using costly solvents [62].

Morsella et al. reported the synthesis of $\mathrm{TiO}_{2}$-lignin composite by coating the $\mathrm{TiO}_{2}$ nanoparticles with lignin as shell via $\mathrm{pH}$-assisted precipitation (entry 5 , Table 2) [63]. The method involves the solubilization of alkali lignin in an alkaline (B) or organic solvent (A) followed by the addition of $\mathrm{TiO}_{2}$ particles. The resulting solution is sonicated to ensure homogenization and finally $\mathrm{TiO}_{2}-$ lignin clusters precipitated out by decreasing the $\mathrm{pH}$ of the solution with the help of acids [63]. The detailed scheme for the synthesis of $\mathrm{TiO}_{2}$-lignin composite is given in Fig. 4.

Also, facile mechano-chemical processes like ball milling can be employed for the preparation of photocatalyst composites based on lignin [64]. For instance, lignin- $\mathrm{TiO}_{2}$ composites were prepared (entry 9, Table 2) through dry and wet milling techniques in a ball mill [65]. In this example, lignin and $\mathrm{TiO}_{2}$ with a mass ratio of 1:1 were milled for $6 \mathrm{~h}$ at $120 \mathrm{rpm}$. The obtained dry milled samples undergo wet milling by the addition of different solvents like water, hexane, or acetone with a solvent mass ratio of 1:2. The obtained composites were filtered and dried around $40{ }^{\circ} \mathrm{C}$ before application [65].

Furthermore, the one-pot in situ method has also been used for the preparation of composite photocatalysts. In this method, firstly the core photoactive particles are synthesized, followed by the addition of the coating agent or the template precursor. The reaction mixture is stirred and the resulting composite is washed, dried, and
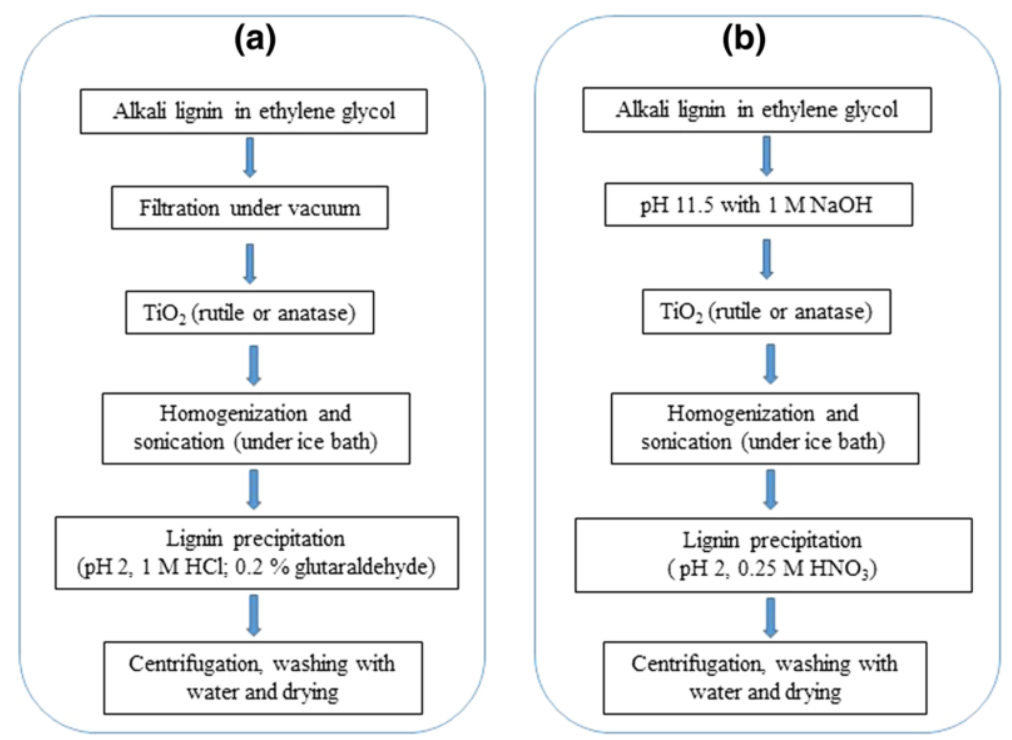

Fig. 4 Detailed protocols adopted for the preparation of the lignin/ $\mathrm{TiO}_{2}$ composite materials [63] 
calcinated [66]. A recent study reports the synthesis of lignin-based carbon- $\mathrm{ZnO}$ nanocomposites using alkali lignin from pulping liquor and zinc nitrate as a precursor for support and $\mathrm{ZnO}$ nanoparticles, respectively [19]. The in situ method is considered to be a low-cost and environmentally friendly technique that can use industrial alkali lignin, while one of the drawbacks of the process is the possibility of the entrapment of impurities between the photoactive core and template $[19,66]$.

Another method used for the preparation of photocatalytic composites is solidphase grinding. This synthesis approach involves the deposition or attachment of a substrate on a polymer support by grinding and mixing. After the completion of the reaction, the precipitates obtained is repeatedly washed with solvents to remove excess reagents [67]. Among the materials prepared by this method, nanocomposites of $\mathrm{CuO}-\mathrm{ZnO}$ were synthesized (entry 2, Table 2) using sodium lignosulphonate as the support and zinc carbonate the precursor for the semiconductor component [68]. One of the advantages of solid-phase synthesis is the easy separation of the reactants from final products by washing and filtration [69]. Similarly, Wang et al. reported the synthesis of a $\mathrm{CuO}$ nano-photocatalyst based on aminated lignin by the solidphase technique [70]. $\mathrm{CuO}$ particles were obtained through direct reaction of sodium hydroxide and copper nitrate with aminated lignin.

\subsubsection{Chemical Interaction Between Lignin and Semiconductor}

The hydroxyl groups along with other functional groups in lignin like carboxyl and carbonyl group can engage in specific interactions with the precursors of functional components such as polymers and photocatalysts during the formation of composites [71, 72]. Recently, lignin has been applied as a template to prepare mesoporous $\mathrm{TiO}_{2}$ nanoparticles using $\mathrm{TiCl}_{4}$ as precursor [72]. The highly electronegative hydroxyl moieties on the surface of the lignin develop a strong affinity towards electropositive metal ions, as shown in Fig. 5. The positively charged $\mathrm{Ti}(\mathrm{OH})_{n}^{(4-n)+}$ formed during the partial hydrolysis of $\mathrm{TiCl}_{4}$ has affinity for the nucleophilic ligand, resulting in adsorption on the surface of lignin via electrostatic forces of attraction. The adsorbed $\mathrm{Ti}(\mathrm{OH})_{n}^{(4-n)+}$ further hydrolyzes and converts to Ti-(O-lignin $)_{4}$ over the surface of the lignin. After complete hydrolysis, well-dispersed $\mathrm{TiO}_{2}$ nanoparticles are formed on the surface of the lignin (Fig. 5) [72, 73].

Amine groups can modify the surface of lignin consequently, increasing the molecular weight as well as the number of active groups on the surface. Synthesis

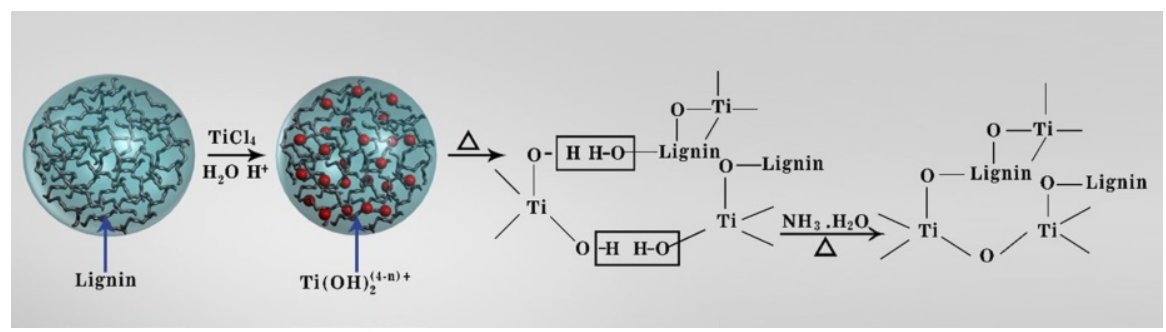

Fig. 5 Formation mechanism of mesoporous $\mathrm{TiO}_{2}$ with lignin as a template [72] 
of porous $\mathrm{ZnO}$ nanoparticles using zinc nitrate $\left[\mathrm{Zn}\left(\mathrm{NO}_{3}\right)_{2}\right]$ and sodium oxalate $\left(\mathrm{Na}_{2} \mathrm{C}_{2} \mathrm{O}_{4}\right)$ and alkali lignin-amine as a template revealed that the ions dissociated from the lignin amine template during the reaction and, attractive electrostatic forces between $\mathrm{Zn}^{2+}$ and $\mathrm{C}_{2} \mathrm{O}_{4}{ }^{2-}$ develop. The hydrogen bonding and van der Waal forces of attraction responsible for the direct contact between the $\mathrm{ZnO}$ particles has been reduced through steric hindrance caused by lignin amine molecule as template, and thus resulted in lower aggregation and generation of smaller-size particles (average of 15-44 nm) [18]. According to the findings, the native lignin is deficient in positively charged functional groups, leading to poor interaction with $\mathrm{ZnO}$ particles $[18,19]$. Introduction of positively charged moieties to the alkali lignin through the process of quaternization developed strong affinity with the negatively charged $\mathrm{ZnO}$ nanoparticles, which was favorable for the fabrication of lignin- $\mathrm{ZnO}$ composite [18].

In another work, lignin-phosphate quaternary ammonium salt (LPQAS) was formed from modifying alkali lignin through a Mannich reaction. LQPAS has been applied as a surfactant for the assembly of $\mathrm{ZnO}$ crystallites via precipitation with $\mathrm{NaOH}$ as the precipitating agent. During the synthesis, LQPAS dissociates into phosphate ions (negatively charged) and quaternary ammonium ions (positively charged). During a chemical reaction, the positively charged quaternary ammonium ions develop an interaction with the negatively charged $\mathrm{OH}^{-}$ions [74]. Subsequently, LQPAS acts as a slightly negatively charged surfactant, which results in an interaction with the positively charged face [001] of $\mathrm{ZnO}$ particles. This interaction represents the driving force for the assembly of $\mathrm{ZnO}$ nanoparticles. Reducing the $\mathrm{pH}$ value to 7 results in the deposition of porous $\mathrm{ZnO}$ nanoparticles. The size of the mesoporous nanoparticles mainly depends on the ratio of $\mathrm{Zn}^{2+}$ and $\mathrm{OH}^{-}$ions, while the surface area of the $\mathrm{ZnO}$ particles is mainly determined by the amount of surfactant molecules rather than the molar ratio of $\mathrm{Zn}^{2+}$ and $\mathrm{OH}^{-}$ions [75].

Lignosulphonates are derivatives of lignin, which can be obtained through the sulfite pulping process and subsequent sulfonation, degradation, and solubilization in water [76]. The functionalization of lignin with various hydrophilic (hydroxyl, sulfonic, and carboxyl groups) and hydrophobic (aliphatic and aromatic groups) moieties results in diverse surface characteristics. Miao et al. applied sodium lignosulphonates (SLS) as template for engineering $\mathrm{ZnO}$ nanomaterials [77]. The reaction proceeds with the interaction of positively charged zinc ions with negatively charged hydroxyl ions, resulting in the formation of $\left[\mathrm{Zn}(\mathrm{OH})_{4}\right]^{2-}$, which is transformed to $\mathrm{Zn}(\mathrm{OH})_{2}$ in an alkaline medium [74] and finally to crystalline $\mathrm{ZnO}$ particles [77]. Morphologically different $\mathrm{ZnO}$ nanomaterial is obtained depending on the aggregation behavior of SLS and the electrostatic interaction developed between the negatively charged (sulfonic and carboxyl) moieties and the positively charged face [001] of $\mathrm{ZnO}$ crystal. Moreover, SLS adsorbed on the surface of $\mathrm{ZnO}$ crystallites prevents the aggregation of particles to some extent and later contributing to the self-assembly of $\mathrm{ZnO}$ particles in the direction of SLS produce secondary superstructures [77].

Varying the amount of SLS causes different degrees of association in the solution and thereby resulting in fabrication of different hierarchical structure of $\mathrm{ZnO}$ nanoparticles. Lowering the concentration of sodium lignosulphonates causes 
aggregation attributed to steric repulsions that result in the formation of bars of $\mathrm{ZnO}$ clusters. Increasing the concentration of sodium lignosulphonates forms a bi-layer structure called mesh-lamina $\mathrm{ZnO}$. Further increase in concentration changes the structure from bilayer to spherical bilayer, ultimately resulting in quasi-spherical particles of $\mathrm{ZnO}$ [77].

SLS have also been used for the surface functionalization of multi-walled carbon nanotubes (MWNTs). Sodium lignosulphonates act as a dispersing agent and are adsorbed on the surface of the MWNTs. $\Pi-\Pi$ non-covalent stacking is mainly responsible for interaction between SLS and MWNTs. SLS is amphiphilic in nature, but dominated by hydrophobic groups with ether and $\mathrm{C}-\mathrm{C}$ bonds. Other than hydrophobic linkages, $\Pi-\Pi$ stacking interactions are also responsible for the adsorption of sodium lignosulphonate on the MWNTs. The steric repulsion caused by sodium lignosulphonate helps in minimizing the van der Waals forces of attraction at the surface contact. The anionic groups on the surface of the sodium lignosulphonate extrude outward to reduce the electrostatic forces of repulsion. The similar charges on the sodium lignosulphonates make MWNTs extremely hydrophilic and, consequently, responsible for their solubility and stability in aqueous medium [78]. SLSfunctionalized MWNTs serves as a potential support for the fabrication of quantum dot hybrids. The uniform deposition of $\mathrm{SnO}_{2}$ and CdS nanoparticles on the SLSfunctionalized MWNTs template comprises the interaction between the positively charged ions of the nanoparticles $\left(\mathrm{Sn}^{4+}\right.$ and $\left.\mathrm{Cd}^{2+}\right)$ and the negatively charged groups of sodium lignosulphonates, as shown in Fig. 6. The SLS-functionalized MWNTs is an outstanding support for the fabrication of quantum dot hybrids ensuring the stability of over 6 months at ambient temperature [79].

\subsubsection{Applications of Lignin-Based Composites in Photocatalysis}

The interest in applying lignin in material engineering is increasing $[9,80]$ specifically in the case of preparing composite materials for photocatalytic applications [72]. The application of lignin as photocatalyst support allows controlling the size of the particles and to obtain a uniform distribution of the particles of the photocatalyst [70]. Additionally, lignin is derived from renewable biomass resource as a byproduct from the pulp and paper industry [81]; consequently, the application of lignin in material engineering will reduce the cost as well as help to fabricate environmentally

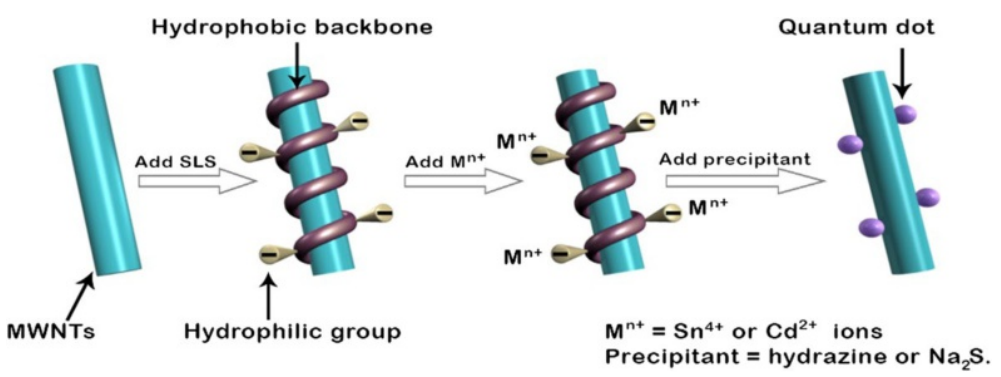

Fig. 6 Mechanism for the Functionalization of MWNTs and quantum dot decoration [79] 
compatible composites. Hence, it is considered to be a promising support for the synthesis of composite photocatalyst. Recently, some attempts have been made to develop lignin-based photoactive composites to improve the efficiency of the photocatalytic process $[18,19]$. In order to overcome the limitations of the photocatalytic reaction, there is a need to understand the basic photophysical and photochemical mechanism of the process. The interaction of photoactive material and light is an important factor in determining the efficiency of the photocatalytic reaction. Nevertheless, the redox reaction can be impeded by the large band gap between valence band and conduction band in the semiconductors [82, 83]. Therefore, high-energy $\mathrm{UV}$ radiation is required for carrying out the photochemical reaction, which is the principal constraint associated in upscaling of a photocatalytic conversion [82, 84].

Lignins form a dark-colored solution in most of the solvents, which makes it photocatalytically inactive, which may reduce the efficiency of the photocatalyst [85]. Nevertheless, it has been observed that lignin can be applied as template for the assembly of stable hybrid photocatalysts. The interaction between the components in the case of composites plays a significant role in determining the photocatalytic performance [86]. The properties of the composites are diverse due to the reinforcing synergy between the components of the hybrid photocatalyst. Consequently, this enhances the transfer and utilization efficacy of photogenerated electrons and intensify the separation of charges that synergistically boost photocatalysis by overcoming the chances of recombination of electrons and holes [82, 83, 86, 87]. Hence, the photocatalytic efficiency could be improved by fabricating a composite of photoactive material and appropriate support. Additionally, the chemical and physical stability of the composite photocatalyst mainly depends on the nature of the support [86]. The use of support stabilizes the textural properties upon thermal treatment, which enhances the disseminations of active sites and usually enhances the catalytic activity of pure oxides $[88,89]$.

Photocatalysts based on lignin semiconductor composites have great potential for the remediation of contaminated water and have received much attention in recent years [19, 72]. The use of lignin as a photocatalyst support would endorse distinctive functionality with excellent physicochemical properties for specific applications accredited to the interaction between semiconductor and support [90]. The following section provides an overview of recent applications of lignin-based composites for contaminant degradation. As reported in the recent literature, the assimilation between lignin and metal oxides, such as $\mathrm{ZnO}, \mathrm{TiO}_{2}$, or $\mathrm{CuO}$, increases the degradation of pollutant compared to pristine metal oxide alone [19, 72, 77].

Lignin-amine (LA) mesoporous zinc oxide hybrid catalyst depicted high sunlight photocatalytic activity. Introduction of amine groups to the lignin via amination reaction improves the surface activity as well as the flocculation and decolorization efficiency for the treatment of wastewater $[81,91]$. The calcination temperature during catalyst preparation plays a significant role in determining the size, morphology, microstructure, and photocatalytic performance of the $\mathrm{ZnO}$ nanophotocatalysts. $\mathrm{ZnO}-\mathrm{LA}$ composite calcined at $400^{\circ} \mathrm{C}$ exhibits higher photocatalytic efficiency than those calcined at 500 and $600{ }^{\circ} \mathrm{C}$. Increasing the temperature from 400 to $600{ }^{\circ} \mathrm{C}$ resulted in an increase in size and decrease in specific surface area of the photocatalyst. In addition, doping of LA with $\mathrm{ZnO}$ precursor also contributes to acquire 
smaller size and high specific surface area of $\mathrm{ZnO}$ nanoparticles by preventing the agglomeration of $\mathrm{ZnO}$ particles. $\mathrm{ZnO}-\mathrm{LA}$ annealed at $400{ }^{\circ} \mathrm{C}$ exhibited photocatalytic degradation efficiency of 99.2 and $96.4 \%$ for methyl orange $\left(20 \mathrm{mg} \mathrm{l}^{-1}\right)$ under UV light irradiation $(1 \mathrm{~h})$ and under solar radiation $(6 \mathrm{~h})$, respectively. The solar photocatalytic performance of $\mathrm{ZnO}-\mathrm{LA}$ is almost the same as that of $\mathrm{TiO}_{2}$ ( $\left.\mathrm{P} 25\right)$ [81]. During a photochemical reaction, the water adsorbed on the surface is oxidized by holes to $\mathrm{OH}$ radicals, while $\mathrm{O}_{2}$ adsorbed on the surface of $\mathrm{ZnO}$ is reduced by the electrons. The hydroxyl radical and superoxide ion formed result in mineralization of methyl orange [90].

In addition to aminated lignin, sodium lingosulphonates have also been used for the fabrication of nano $\mathrm{ZnO}$ photocatalyst. Different $\mathrm{ZnO}$ morphologies such as nanoparticle-bar, nanomesh-lamina, and quasi-nanosphere were acquired [77], depending on the concentration and aggregation of sulphonated lignin and electrostatic interaction between the sulphonated lignin and $\mathrm{ZnO}$ crystals. The lignosulphonates-nanomesh $\mathrm{ZnO}$ composite displayed 100\% degradation efficiency for methylene blue (5 ppm) under UV irradiation power of $12 \mathrm{~W}$ within 90 min (see entry 7, Table 3 for effect of irradiation power on degradation efficiency) [77]. In the course of photocatalytic degradation, holes generated react with either hydroxyl ions or adsorbed water molecules and form hydroxyl radicals. Simultaneously, the interaction of $\mathrm{O}_{2}$ molecules and electrons produce superoxide anion radicals. Finally, the interaction of superoxide anion radicals and hydroxyl radicals with methylene blue results in its degradation [77, 92]. Compared to pristine $\mathrm{ZnO}$ particles, lignosulphonate-doped $\mathrm{ZnO}$ particles exhibited high photocatalytic efficiency due to improve surface state, high specific surface area with more hydroxyl groups, and smaller band gap of $\mathrm{ZnO}$ particles [93].

Moreover, quaternized alkali lignin-ZnO hybrid have been applied for the degradation of Rhodamine B (Rh B) and methyl orange (MO). Yet again, efficiency of composite is far better than the pure $\mathrm{ZnO}$. After the light irradiation (see entry 3, Table 3 for light source details) for $30 \mathrm{~min}$, methyl orange $\left(15 \mathrm{mg} \mathrm{l}^{-1}\right)$, was completely degraded by the composite while pure $\mathrm{ZnO}$ showed $75.3 \%$ degradation efficiency even after $50 \mathrm{~min}$. Quaternized alkali lignin-ZnO exhibited lower degradation efficiency for $15 \mathrm{mg} \mathrm{l}^{-1}$ Rhodamine B (79.2\%) compared to methyl orange but was higher than that of pure $\mathrm{ZnO}(31.1 \%)$. Methyl orange mainly degraded by holes, accredited to the negative charge of the dye pushed towards $\mathrm{ZnO}$ as shown in Fig. 7. Whereas, the degradation of Rhodamine $\mathrm{B}$ is driven by $\mathrm{O}_{2}{ }^{-}$and $\mathrm{OH}$ radicals due to their strong oxidative abilities [18]. The applied composites were rather stable and no obvious decrease in photodegradation efficiency was observed in three successive recycling tests [18]. Thus, doping with carbon materials improved the efficiency of $\mathrm{ZnO}$ by inhibiting the photocorrosion of $\mathrm{ZnO}$ [19] and overcoming the limitation associated with the pure $\mathrm{ZnO}$ as photocatalyst such as charge separation and low quantum efficiency [94].

Similarly, porous carbon-based $\mathrm{CeO}_{2}$ composites were fabricated applying lignin as support. Lignin decomposition contribute to the porosity of the template and ensure the uniform growth of $\mathrm{CeO}_{2}$ nanorods to carbon-- $\mathrm{CeO}_{2}$ composite (Fig. 8).

The photocatalytic activity of carbon- $\mathrm{CeO}_{2}$ hybrid was determined for the desulfurization of $\mathrm{SO}_{2}$, which is extremely injurious to human health as well as for the 


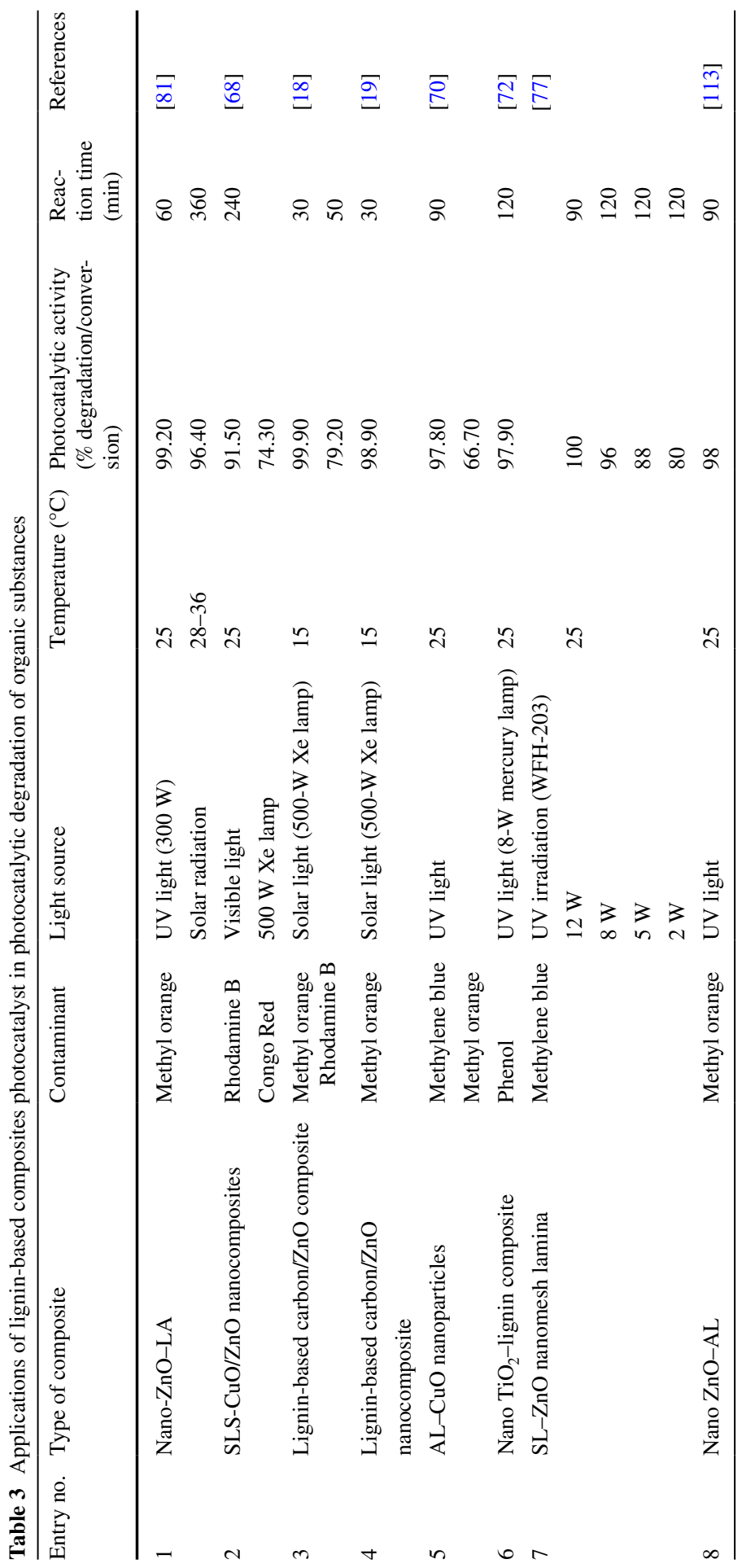




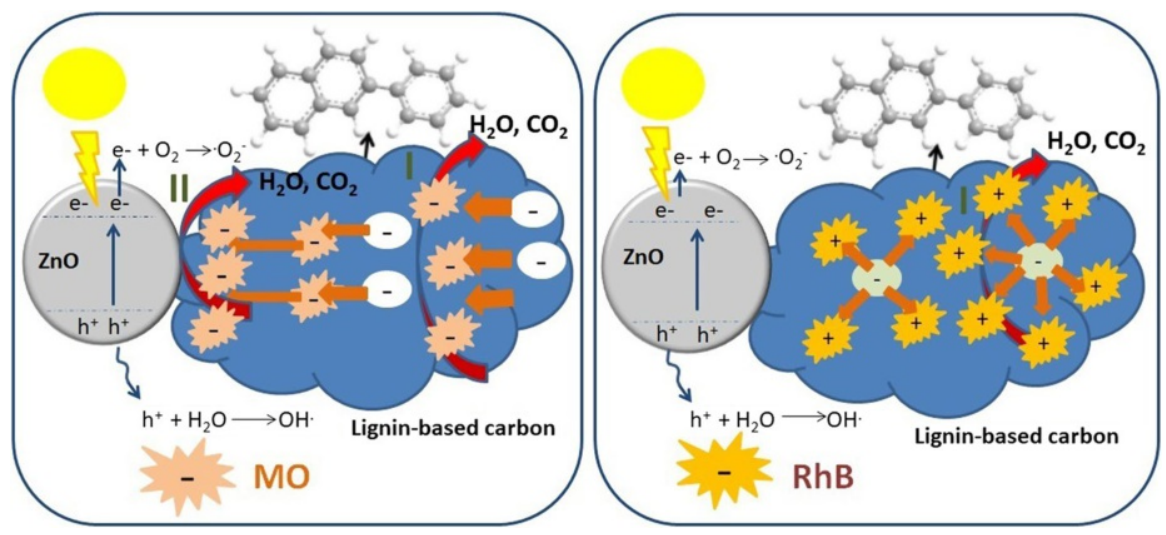

Fig. 7 Photocatalytic mechanism for the degradation of $\mathrm{MO}$ (a) and $\mathrm{RhB}(\mathbf{b})$ over the $\mathrm{LC}-\mathrm{ZnO}$ composite [18]

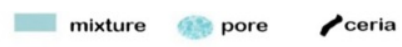

(a) (b)

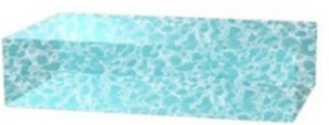

(c)

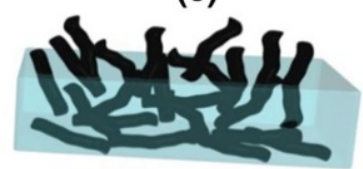

Fig. 8 Formation mechanism of porous carbon- $\mathrm{CeO}_{2}$ composite. a Blend of lignin and cerium nitrate. b Partially decomposed porous lignin. $\mathbf{c}$ Porous carbon $\mathrm{CeO}_{2}$ composite [20]

environment. $\mathrm{CeO}_{2}$ plays a significant role in trapping $\mathrm{SO}_{2}$ molecules, oxygen storage, and oxidizing ability of $\mathrm{CeO}_{2}$ results in chemisorption of $\mathrm{SO}_{2}$. Lignin support not only takes part in physisorption but is also involved in photocatalytic conversion of $\mathrm{SO}_{2}$ $[20,95]$. The reaction initiated with physical adsorption of $\mathrm{SO}_{2}$, and then chemisorption took place simultaneously due to the oxidizing and oxygen storage properties of $\mathrm{CeO}_{2}$. Porous carbon $\mathrm{CeO}_{2}$ hybrid exhibited high desulfurization efficiency and significantly oxidize the adsorbed $\mathrm{SO}_{2}$ with conversion ratio of $51.8 \%$. Carbon- $\mathrm{CeO}_{2}$ showed improved photocatalytic performance compared to pristine $\mathrm{CeO}_{2}$, which is attributed to the possible involvement of carbon during a reaction.

The reaction mechanism for the desulfurization of $\mathrm{SO}_{2}$ is as follows (Reactions 1-3) [21]

$$
(1 / 2) x \mathrm{O}_{2}+x \mathrm{C} \rightarrow x \mathrm{C}(\mathrm{O})
$$

The reaction proceeds with the formation of active site $\mathrm{C}(\mathrm{O})$ that later is converted to carbon-oxygen complex, which provides oxygen for the photocatalytic reaction. $\mathrm{SO}_{2}$ reacts with the holes and $\mathrm{O}_{2}$ from the $\mathrm{CeO}_{2}$, and is thereby converted to $\mathrm{SO}_{3}$ (Fig. 9). The electrons on the surface of the catalyst react with the carbon-oxygen complex, simultaneously $\mathrm{CeO}_{2}$ retains the $\mathrm{O}_{2}$ and generates carbon [20].

$$
\mathrm{CeO}_{2}+x \mathrm{SO}_{2} \rightarrow x \mathrm{SO}_{3}+\mathrm{CeO}_{2-x}
$$


Fig. 9 Desulfurization mechanism of porous carbon- $\mathrm{CeO}_{2}$ composites [20]

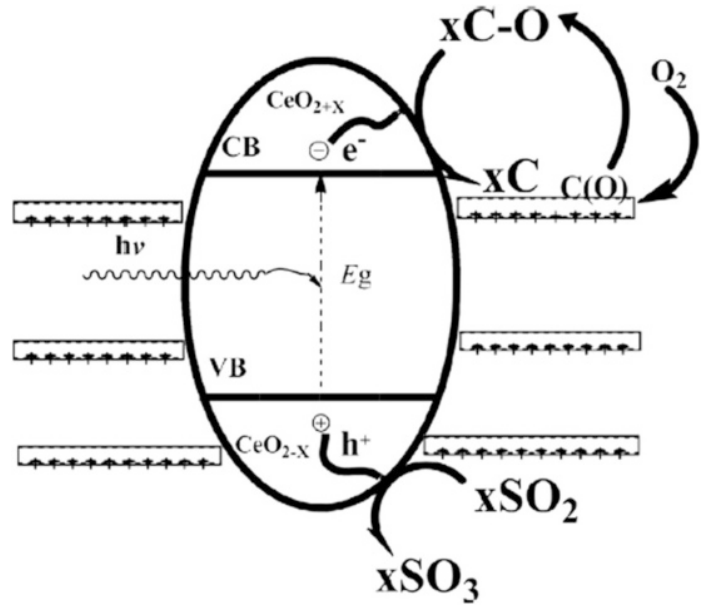

$$
\mathrm{CeO}_{2-x}+x \mathrm{C}-\mathrm{O} \rightarrow x \mathrm{C}+\mathrm{CeO}_{2}
$$

There are very few studies reported on the utilization of lignin as support for the synthesis of mesoporous $\mathrm{TiO}_{2}$ photocatalyst. Chen et al. synthesized mesoporous $\mathrm{TiO}_{2}$ composite using $\mathrm{TiCl}_{4}$ as the reactant and lignin as the template [72]. The synthesized photocatalyst was used for phenol $\left(0.05 \mathrm{~g} \mathrm{l}^{-1}\right)$ degradation under UV light, resulting in degradation of $97.9 \%$ of phenol in 120 min (entry 6, Table 3). The photocatalytic performance of $\mathrm{TiO}_{2}$-lignin composite was reported to be higher than the $\mathrm{TiO}_{2}$ synthesized without template and commercial $\mathrm{TiO}_{2} \mathrm{P} 25$ that showed phenol degradation efficiency of 76.3 and $86.3 \%$, respectively. The high photocatalytic activity of $\mathrm{TiO}_{2}$-lignin composite is due to the high electronegativity difference between lignin and $\mathrm{TiO}_{2}$ precursor that contributes to its uniform distribution for the formation of mesoporous $\mathrm{TiO}_{2}$ particles. The lower surface hydroxyl group on $\mathrm{TiO}_{2}$-lignin is another factor for the superior photocatalytic efficiency of composite that is ascribed to the stronger interaction between surface hydroxyl groups of $\mathrm{TiO}_{2}$ precursor and lignin hydroxyl groups during hydrolysis. Moreover, lignin also contributes to the smaller crystal size and high specific surface area that ultimately improved the photocatalytic performance of the composite [72].

Recently, cupric oxide ( $\mathrm{CuO})$, a $p$-type semiconductor, has gained much attention as a photocatalyst due to its narrow band gap $(1.2 \mathrm{eV})$. It has been widely used as a photocatalyst $[96,97]$ for the degradation of pollutants [97] and for the production of $\mathrm{H}_{2}$ gas [98]. The size, morphology, microstructure, and photocatalytic performance of $\mathrm{CuO}$ nanoparticles was found to be enhanced by using aminated lignin (AL) as template. Calcination temperature and AL amount play a significant role in determining the photocatalytic activity of the $\mathrm{CuO}-\mathrm{AL}$ composite. Under UV light irradiation for $90 \mathrm{~min}, \mathrm{CuO}$ doped with $\mathrm{AL}(0.5 \mathrm{~g})$ exhibited considerably higher photodegradation of $10 \mathrm{mg} \mathrm{l}^{-1}$ methylene blue (97.8\%) and $10 \mathrm{mg} \mathrm{l}^{-1}$ methyl orange (66.7\%) compared to undoped $\mathrm{CuO}$. The optimum calcination temperature for $\mathrm{CuO}$ catalyst was $400{ }^{\circ} \mathrm{C}$, which yields smaller crystallite size and high surface 
area, thus improving the photodegradation rate of organic dyes. Low temperature $\left(300{ }^{\circ} \mathrm{C}\right)$ leads to incomplete decomposition of aminated lignin while high temperature $\left(500{ }^{\circ} \mathrm{C}\right)$ resulted in aggregation of particles. The optimum dosage of aminated lignin for $\mathrm{CuO}$ doping was $0.5 \mathrm{~g}$; further increase in dosage resulted in larger crystal size due to aggregation [70]. Moreover, optimizing the dosage and calcination temperature, the photocatalytic performance of the lignin-based composites can be maximized, in agreement with other studies [81].

\subsection{Applications of Lignin-Based Materials in Photovoltaics}

Appropriate engineering of photovoltaic cells is required for optimum light harvesting capacity and improved photo-inductive charge transfer [99]. The interface engineering of the anode is of utmost significance to improve the efficiency of the cell [100]. A power conversion efficiency of $10 \%$ has been achieved through cathode modification. However, in case of the anode, water-soluble conductive polymer poly(3,4-ethylene dioxythiophene):poly(styrene sulfonic acid) (PEDOT:PSS) has been widely used. The efficiency of the PEDOT:PSS principally driven by the conductivity and highest occupied molecular orbital (HOMO) energy level. In order to control HOMO energy level, perfluorinated ionomer (PFI) was applied as dopant for PEDOT, which exhibited better efficiency than PEDOT:PSS [101]. Similarly, the use of PSS as dopant also improved the conductivity of PEDOT [102]. Nevertheless, the microstructural and electrical inhomogeneities caused by PSS due to its non-conjugated structure configure PEDOT:PSS unsuitable for hole injection layer (HIL) [103].

The development of hole transport materials based on biomaterials are of great interest in the field of organic electronic devices. Lignin and its derivatives contain several aromatic rings that strongly absorb in the ultraviolet range of the electromagnetic spectrum [104]. In organic electronic devices, hole transport process is associated with the oxidation of electron-rich compounds such as thiophene in PEDOT:PSS and carbazole in poly(vinylcarbazole). Lignosulfonate poses exceptional hole-transfer characteristics owing to oxidation of phenols and $\mathrm{j}$ aggregation phenomenon. The aggregation behavior is responsible for the semiconductive nature of lignosulfonates [105].

Recently, various attempts have been made to improve the conductivity of PEDOT:PSS through different additives such as ionic liquids, surfactants, and organic solvents. Post-treatment of PEDOT:PSS with inorganic acid, polar solvents, salts, and zwitterions significantly enhanced the conductivity of PEDOT [106]. To significantly improve the conductivity and reduce the production cost, there is a need for renewable dopant to boost this technology. In view of green chemistry and green economics, lignin derivatives, as an alternative semiconductive material, have been employed as dopant for PEDOT. Li et al. investigated the potential of lignosulfonate (SL) and alkyl chain cross-linked lignosulfonate polymer (ASL) obtained by the introduction of alkyl chain to sulfomethylated lignin, as hole transport material for solar cells [105]. The mass ratio of PEDOT:SL has not shown considerable change in PCEs of the cell (see entry 2, Table 4 for detailed photovoltaic performance), 


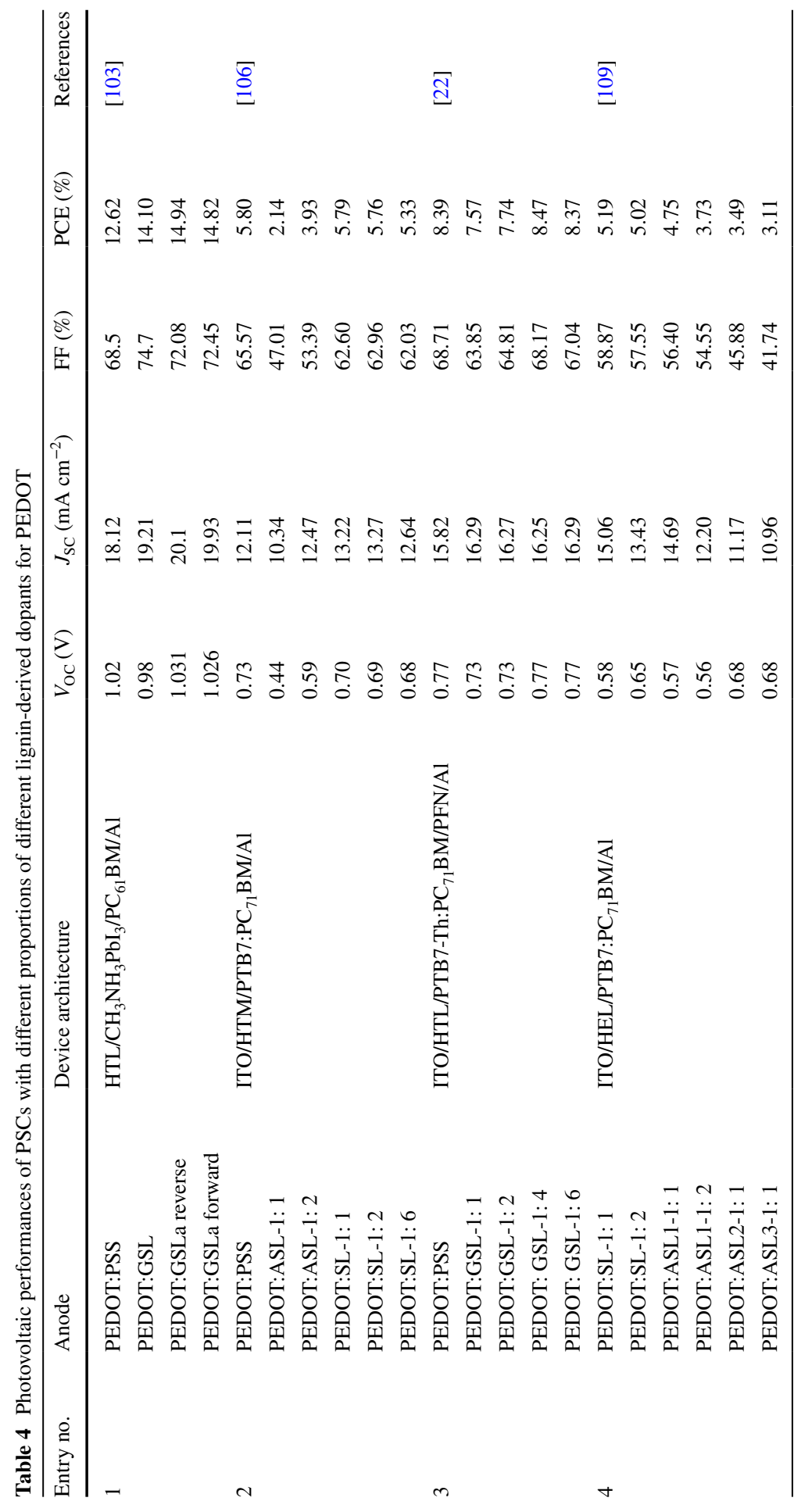


with PEDOT:SL mass ratio of 1:1, 1:2, and 1:3, PCEs exhibited by the device (ITO/ HTM/PTB7:PC ${ }_{71} \mathrm{BM} / \mathrm{Al}$ ) were $5.79,5.76$, and $5.33 \%$, respectively [105]. The PCE of PEDOT:SL is quite close to PEDOT:PSS (4.28 and 4.50\%) as reported in the literature $[107,108]$. Moreover, the results of PCEs of PEDOT:ASL with mass ratios of $1: 1$ and $1: 2$ were 2.14 and $3.93 \%$, respectively. The results obtained depicted the positive influence of phenolic groups in lignosulfonates on the hole transport features of the materials. The hole mobility of lignosulfonate polymer is comparatively lower than lignosulfonate due to the reduced content of phenolic hydroxyl groups. The surface and nanoaggregate size of the film also contribute to the hole transport properties of the materials. The unique surface and variable size of nanoaggregates among PEDOT:SL and PEDOT:ASL films leads to the different hole transport properties of both materials [105].

$\mathrm{Wu}$ et al. reported the application of grafted sulfonated acetone-formaldehyde lignin (GSL), as a $p$-type semiconductive dopant for hole extracting layer [103]. GSL is a polymeric semiconductor derived by grafting the sulfonated acetone-formaldehyde (SAF) to alkali lignin (AL). The long aliphatic chain and large number of sulfonic groups on GSL make it a fine dispersant for being used as dopant for PEDOT. The conjugated structure of GSL makes it a good candidate for electron-hole mobility similar to other conjugated polymers used in organic electronics. GSL as hole transporting layer has shown promising results with the hole mobility of $2.27 \times 10^{-6}$ $\mathrm{cm}^{2} \mathrm{~V}^{-1} \mathrm{~s}^{-1}$ attributed to large number of hydroxyl moieties. Furthermore, GSL:PEDOT exhibited better conductivity and power conversion efficiency up to $14.94 \%$ than PEDOT:PSS (12.6\%) with the device structure of $\mathrm{HTL} / \mathrm{CH}_{3} \mathrm{NH}_{3} \mathrm{PbI}_{3} /$ $\mathrm{PC}_{61} \mathrm{BM} / \mathrm{Al}$. The high efficiency of PEDOT:GSL is credited to the homogeneity and uniformity of the film surface, which is instigated by highly disperse GSL. Altogether, it will improve performance of the device by increasing charge transfer properties [103]. Furthermore, larger grain size of the PEDOT:GSL film results in higher current density [49]. Indium tin oxide (ITO) modified by PEDOT:GSL exhibited larger grain size $(67 \mathrm{~nm})$ than ITO transformed by PEDOT:PSS $(61 \mathrm{~nm})$. Consequently, PEDOT:GSL modified ITO as hole-extraction layer has better transport characteristics for hole collection due to its conjugated structure than PEDOT:PSS that lacks a conjugated structure [103].

SL and ASL have exceptional properties of forming Block-like self-assembly without any external interface in particular solvents. During the oxidation of SL, characteristic aggregation behavior is acquired by SL and ASL through the electron transport mechanism and their self-assembly. SL acquires distinctive assembly, attributable to its amphiphilic nature and presence of benzene rings that leads to its aggregation in particular solvents through $\Pi-\Pi$ interactions and $\mathrm{CH}-\Pi$ interaction. With 1:3 $\mathrm{H}_{2} \mathrm{O}$ : ethanol solution, the aggregates acquired for SL were of nano size, while micro-sized aggregates were obtained for ASL in the same set of conditions. Block-like aggregation behavior was more dominant in ASL compared to SL due to cross-linked alkyl chain polymerization in SL. Based on the aggregation behavior and electron transport characteristics of the SL and ASL, the materials have been applied as dopants to improve the conductivity of PEDOT [109]. The power conversion efficiency of polymer solar cell also depends on the aggregation behavior of the dopants that is ultimately 
affected by the hydroxyl group content [105, 109]. Moreover, the oxidative capacity of SL is much better than ASL due to the high phenolic hydroxyl group content. The reaction proceeds with the formation of radical cations and phenol radicals, formed by the oxidation of SL and phenolic hydroxyl groups, respectively. With ITO/HEL/PTB7:PC ${ }_{71} \mathrm{BM} / \mathrm{Al}$ device structure, the maximum PCE showed by PEDOT:SL with mass ratio of $1: 1$ was $5.19 \%$ that shows the potential of SL as effective dopant for PEDOT in organic electronic devices. SL exhibited the hole mobility of $2.95 \times 10^{-6} \mathrm{~cm}^{2} \mathrm{~V}^{-1} \mathrm{~s}^{-1}$, which is higher in comparison to ASL that showed the hole mobility of $3.18 \times 10^{-7} \mathrm{~cm}^{2} \mathrm{~V}^{-1} \mathrm{~s}^{-1}$. The results of the study also showed that hydroxyl group content is directly related to the hole mobility and PCE, whereas increase in hydroxyl group increased hole transport ability and PCEs and vice versa. Furthermore, the high pH of SL and ASL is an advantage of the conductive polymers over conventional dopant PSS that will prevent corrosion of ITO layers [109].

Hong et al. also investigated the GSL as potential dopant and stabilizer for PEDOT to enhance the performance of light-emitting and photovoltaic devices [22]. PEDOT:GSL films and aqueous dispersions with adjustable conductivities and work functions have been used for fabricating high-performance organic light-emitting diodes and polymer solar cells [22]. GSL has a number of advantages over other lignin-derived polymers such as lignosulfonates applied as dopant for PEDOT. GSL has high phenolic content that results in better oxidative capability of the polymer. The high degree of sulfonic group in GSL compared to lignosulfonate makes it a more suitable dispersant for excellent PEDOT dispersion. The addition of GSL in PEDOT also results in better film characteristics in comparison to PEDOT modified by lignosulfonate attributed to the superior dispersing characteristics of GSL. Altogether, the superior GSL contribute in improving the hole transport properties of PEDOT as a dopant. The oxidation peak of GSL-doped electrode obtained at $1.1 \mathrm{~V}$ that indicates that GSL HOMO energy level is $-5.5 \mathrm{eV}$ and its oxidation can take place at comparatively low potential. GSL as hole transporting material exhibited a good hole mobility $\left(2.27 \times 10^{-6} \mathrm{~cm}^{2} \mathrm{~V}^{-1} \mathrm{~s}^{-1}\right)$ credited to its phenolic structure. The power efficiency of PEDOT:GSL with the mass ratios of 1:1, 1:2, 1:4, and 1:6 were $1.51,6.04,12.91$, and $14.67 \mathrm{lmW}^{-1}$, respectively. It is evident by the power efficiencies that by increasing the GSL content the hole injection and transport properties were improved. Similarly, PEDOT:GSL 1:4 and 1:6 displayed far better power efficiency than PEDOT:PSS $\left(8.251 \mathrm{~mW}^{-1}\right)$. Using the device structure of ITO/HTL/PTB7-Th:PC ${ }_{71} \mathrm{BM} / \mathrm{PFN} / \mathrm{Al}$, the PCEs of PEDOT:GSL with mass ratios of $1: 4$ and $1: 6$ was 8.47 and $8.37 \%$, respectively, which is quite analogous to PEDOT:PSS (8.39\%) (entry 3, Table 4). Moreover, the homogenous film surface of PEDOT:GSL results in enhancement of hole injection features of the material due to the excellent dispersion property of GSL. Another important function for organic electronic devices is work function that also increases with increasing GSL content. The work function of PEDOT:GSL with mass ratios of $1: 2,1: 4$, and $1: 6$ were $4.92,5.05$, and $5.10 \mathrm{eV}$, respectively, which is comparable to PEDOT:PSS (5.02 eV) [22]. 


\section{Conclusions, Future Perspectives, and Challenges}

In this review, we discussed the recent progress in the field of photocatalysis and photovoltaics with a focus on lignin-based composite materials. The aims were to review the recent studies on the application of lignin-based materials for photocatalysis and photovoltaics-related environmental remediation and energy conversion, respectively, which will provide some useful implications for future research. Lignin as a biopolymer support showed promising potential in the field of heterogeneous photocatalysis explicitly in the context of the degradation of unwanted contaminants in the environment. A number of studies have reported the use of lignin as a commendable template for photocatalyst synthesis [18] attributed to its high specific surface area that improves the physical adsorption of the substrate [20] and superior photoelectron transfer characteristics owing to unique surface contact [18]. In addition, lignin-based composite materials have great potential to replace cost-intensive materials like graphene in the field of photocatalysis. The photodegradation efficiency of graphene oxide-based composites for methyl orange, methylene blue, and Rhodamine B were 87.2, 85.1, and $73.9 \%$, after 60 min of UV photodegradation, respectively [110]. Lignin composite possesses excellent photocatalytic activity (see Table 3 for details), which is superior to those of graphene.

Many methods are suitable for the preparation of lignin-based composites. However, $\mathrm{pH}$-assisted precipitation and solid-phase grinding have attracted increasing attention and some promising results have been reported. In future research on the photocatalysis via lignin-based composites, detailed investigations on the interaction of composite and substrate should be performed. Moreover, prospective applications may be expected in the field of photoelectric conversion [19], and for electrochemical storage systems [42], such as supercapacitors [15].

There are a number of studies discussed in this review demonstrating that lignin-based materials have wide applications in diverse fields ranging from photocatalysis to electrochemical energy devices and biomedicine. Developing lignin into functional materials, specifically its application as a support for solid composite photocatalysts, would present a great success. Moreover, lignin-based composites show improved photocatalytic efficiency, e.g., for the degradation of pollutants in aqueous media. Nevertheless, a deeper understanding of the underlying mechanism of interaction of lignin and the photoactive material are in demand.

Although considerable advancement has been made in materials development and understanding the structure-property relationships of organic photovoltaics materials and devices, there are still numerous open questions that need to be answered to achieve an increase in the photoconversion efficiency in order to reach at an economically feasible utilization. Particularly, the charge-carrier separation and mobility within the materials has to be improved. There are very few studies that have explored the potential of lignin as dopant for anode in photovoltaic devices. However, recent success in development of lignosulfonate-based dopants for semiconductive polymers with PCE analogous to PSS (see Table 4 
for comparison) will pave the way for future research in lignin-based high-performance organic devices. Further research is required to understand the origin of such substantial electron transport properties of lignin as well as the mechanism of the lignin-based photovoltaic cells with improved performance.

The valorization of lignin not only encompasses technical and scientific developments but also economic aspects. There are striking opportunities for an economic gain from lignin valorization attributed to its low cost and profuse availability as a byproduct of the pulping industry and bioethanol refineries. Hence, the potential to apply the underutilized lignin sources stimulates the aspiration not only for the development of efficient isolation methods but also for the fabrication of new ligninbased products, which have high economic value in the coming years.

Acknowledgements This publication is part of a project that has received funding from the European Union's Horizon 2020 research and innovation programme under the Marie Skłodowska-Curie grant agreement No. 711859 and from the financial resources for science in the years 2017-2021 awarded for the implementation of an international co-financed project. Prof. Dr. J.C. Colmenares and Dr. V. Nair are very grateful for the partial support from the National Science Centre in Poland within Sonata Bis Project No. 2015/18/E/ST5/00306. Roger Gläser gratefully acknowledges support from the Leipzig Graduate School of Natural Sciences: Building with Molecules and Nano-objects as well as from the Research Academy Leipzig.

Open Access This article is distributed under the terms of the Creative Commons Attribution 4.0 International License (http://creativecommons.org/licenses/by/4.0/), which permits unrestricted use, distribution, and reproduction in any medium, provided you give appropriate credit to the original author(s) and the source, provide a link to the Creative Commons license, and indicate if changes were made.

\section{References}

1. Tuck CO, Perez E, Horvath IT, Sheldon RA, Poliakoff M (2012) Science 337:695-699

2. Zeng X, Yao G, Wang Y, Jin F (2014) In: Jin F (ed) Application of hydrothermal reactions to biomass conversion. Springer, Berlin

3. Ren X, Wang P, Han X, Zhang G, Gu J, Ding C, Zheng X, Cao F (2017) ACS Sustain Chem Eng 5:6548-6556

4. Guan Q, Mao T, Zhang Q, Miao R, Ning P, Gu J, Tian S, Chen Q, Chai XS (2014) J Supercrit Fluids 95:413-421

5. Agrawal A, Kaushik N, Biswas S (2014) Scitech J 01:32-36

6. Hu J, Zhang Q, Lee DJ (2018) Bioresour Technol 247:1181-1183

7. Chatel G, De Oliveira Vigier K, Jérôme F (2014) ChemSusChem 7:2774-2787

8. Pu Y, Zhang D, Sigh PM, Ragauskas AJ (2008) Biofuels Bioprod Biorefin 2:58-73

9. Upton BM, Kasko AM (2016) Chem Rev 116:2275-2306

10. Zakzeski J, Bruijnincx PCA, Jongerius AL, Weckhuysen BM (2010) Chem Rev 110:3552-3599

11. Li SH, Liu S, Colmenares JC, Xu YJ (2016) Green Chem 18:594-607

12. Lee HV, Hamid SBA, Zain SK (2014) Sci World J 2014:1-20

13. Dorrestijn E, Laarhoven LJJ, Arends IWCE, Mulder P (2000) J Anal Appl Pyrolysis 54:153-192

14. Lu H, Zhao XS (2017) Sustain Energy Fuels 1:1265-1281

15. Richter AP, Bharti B, Armstrong HB, Brown JS, Plemmons D, Paunov VN, Stoyanov SD, Velev OD (2016) Langmuir 32:6468-6477

16. Lignin Market (Lignosulfonates, Kraft Lignin and others) for concrete additive, animal feed, dye stuff, and other applications: global industry perspective, comprehensive analysis and forecast 2014-2020. Market Research Store, Deerfield Beach. https://www.globe.com.ph/

17. Kun D, Pukánszky B (2017) Eur Polym J 93:618-641 
18. Wang H, Qiua X, Liua W, Yang D (2017) Appl Surf Sci 426:206-216

19. Wang H, Qiu X, Zhong R, Fu F, Qian Y, Yang D (2017) Mater Chem Phys 199:193-202

20. Wang N, Fan H, Ai S (2015) Chem Eng J 260:785-790

21. Wang W, Tade MO, Shao Z (2015) Chem Soc Rev 44:5371-5408

22. Hong N, Xiao J, Li Y, Li Y, Wu Y, Yu W, Qiu X, Chen R, Yip HL, Huangd W, Cao Y (2016) J Mater Chem C 4:5297-5306

23. Virkutyte J, Jegatheesan V, Varma RS (2012) Bioresour Technol 113:288-293

24. Naseem A, Tabasum S, Zia KM, Zuber M, Ali M, Noreen A (2016) Int J Biol Macromol 93:296-313

25. Doherty WOS, Mousavioun P, Fellows CM (2011) Ind Crops Prod 33:259-276

26. Sjöström E (1993) Wood chemistry. Fundamentals and applications. Academic Press, San Diego

27. Smook GA (2002) Handbook for pulp and paper technologies. Angus Wilde Publications Inc., Vancouver

28. Watt C, Burgess H (1854) Improvement in the manufacture of paper from wood. US 11343

29. Koljonen K, Österberg M, Kleen M, Fuhrmann A, Stenius P (2004) Cellulose 11:209-224

30. Wunderlich B, Bodily DM, Kaplan MH (1964) J Appl Phys 35:95-102

31. Faix O, Meier D, Grobe I (1987) J Anal Appl Pyrolysis 11:403-416

32. Chauvette G, Heitz M, Rubio M, Khorami J, Chornet E, Menard H (1985) Thermochim Acta 84:1-5

33. Yang W, Owczarek JS, Fortunati E, Kozanecki M, Mazzaglia A, Balestra GM, Kenny JM, Torre L, Puglia D (2016) Ind Crops Prod 94:800-811

34. Barana D, Ali SD, Salanti A, Orlandi M, Castellani L, Hanel T, Zoia L (2016) ACS Sustain Chem Eng 4:5258-5267

35. Sarkanen KV, Ludwig CH (1971) Lignins occurrence formation structure and reactions. John Wiley and Sons, New York

36. Gupta VG, Tuohy M, Kubicek CP, Saddler J, Xu F (2014) Bioenergy research: advances and applications. Elsevier, Amsterdam

37. Thakur VK, Thakur MK, Raghavan P, Kessler MR (2014) ACS Sustain Chem Eng 2:1072-1092

38. Morandim-Giannetti AA, Agnelli JAM, Lancas BZ, Magnabosco R, Casarin SA, Bettini SHP (2012) Carbohydr Polym 87:2563-2568

39. Evans A, Strezov V, Evans T (2010) Energy Rev 14:1419-1427

40. Lima RB, Raza R, Qin H, Li J, Lindstromac ME, Zhu B (2013) RSC Adv 3:5083-5089

41. Jeon JW, Zhang LB, Lutkenhaus J, Laskar D, Lemmon J, Choi D, Nandasiri MI, Hashmi A, Xu J, Motkuri RK, Fernandez CA, Liu J, Tucker MP, McGrail PB, Yang B, Nune SK (2015) ChemSusChem 8:428-432

42. Geng X, Zhang Y, Jiao L, Yang L, Hamel J, Giummarella N, Henriksson G, Zhang L, Zhu H (2017) ACS Sustain Chem Eng 5:3553-3561

43. Shi M, Wei W, Jiang Z, Han H, Gaoa J, Xie J (2016) RSC Adv 6:25255-25266

44. Colmenares JC, Varma RS, Lisowski P (2016) Green Chem 18:5736-5750

45. Dai K, Zhang XH, Fan K, Zeng P, Peng TY (2014) J Nanomater 2014:694073-694080

46. Leary R, Westwood A (2011) Carbon 49:741-772

47. Khan G, Kim YK, Choi SK, Han DS, Wahab AA, Park H (2013) Bull Korean Chem Soc 34:1137-1144

48. Bagheri S, Julkapli NM, Hamid SBA (2015) Int J Photoenergy 1:1-30

49. Dong SS, Zhang JB, Gao LL, Wang YL, Zhou DD (2012) Trans Nonferrous Met Soc China 22:2477-2483

50. Lisowski P, Colmenares JC, Mašek O, Lisowski W, Lisovytskiy D, Kamińska A, Łomot D (2017) ACS Sustain Chem Eng 5:6274-6287

51. Ke D, Liu S, Dai K, Zhou J, Zhang L, Peng T (2009) J Phys Chem C 113:16021-16026

52. Zeng J, Liu S, Cai J, Zhang L (2010) J Phys Chem C 114:7806-7811

53. Paridaa B, Iniyanb S, Goic R (2011) Renew Sust Energ Rev 15:1625-1636

54. Yu J, Zheng Y, Huang J (2014) Polymers 6:2473-2509

55. Nazeeruddin MK, Baranoff E, Grätzel M (2011) Sol Energy 85:1172-1178

56. Gan Q, Bartoli FJ, Kafafi ZH (2013) Adv Mater 25:2385-2396

57. Spanggaard H, Krebs FC (2004) Sol Energy Mater Sol Cells 83:125-146

58. Zhou Y, Fuentes-Hernandez C, Khan TM, Liu JC, Hsu J, Shim JW, Dindar A, Youngblood JP, Moon RJ, Kippelen B (2013) Sci Rep 3:1536-1540 
59. Hu L, Zheng G, Yao J, Liu N, Weil B, Eskilsson M, Karabulut E, Ruan Z, Fan S, Bloking JT, McGehee MD, Wagberg L, Cui Y (2013) Energy Environ Sci 6:513-518

60. Chiba Y, Islam A, Watanabe Y, Komiya RN, Koide LH (2006) Jpn J Appl Phys 45:638-640

61. Salvador GP, Pugliese D, Bella F, Chiappone A, Sacco A, Bianco S, Quaglio M (2014) Electrochim Acta 146:44-51

62. Hendrix Y, Lazaro A, Yu Q, Brouwers L (2015) World J Nanosci Eng 5:161-177

63. Morsella M, Giammatteo M, Arrizza L, Tonucci L, Bressana M, d'Alessandro N (2015) RSC Adv 5(57453):57461

64. Zhou J, Zhang M, Zhu Y (2015) Phys Chem Chem Phys 17:3647-3652

65. Nair V, Dhar P, Vinu R (2016) RSC Adv 6:18204-18216

66. Altavilla C (2016) Upconverting nanomaterials: perspectives, synthesis, and applications. CRC Press, New York

67. Neckers DC (1975) J Chem Educ 52:695-702

68. Wu F, Wang X, Hu S, Hao C, Gao H, Zhou S (2017) Int J Hydrog Energy 42:30098-30108

69. Hodge P, Sherrington DC (1980) Polymer-supported reactions in organic synthesis. John Wiley \& Sons, Chichester

70. Wang X, Wu F, Duan Y, Wang Y, Hao C, Ge C (2016) RSC Adv 6:65644-65653

71. Jin W, Zhang Z, Wu G, Tolba R, Chen A (2014) RSC Adv 4:27843-27849

72. Chen X, Kuo DH, Lu D, Hou Y, Kuo YR (2016) Microporous Mesoporous Mater 223:145-151

73. Zhou Y, Ding EY, Li WD (2007) Mater Lett 61:5050-5052

74. Xingfu Z, Zhaolin H, Yiqun F, Su C, Weiping D, Nanping X (2008) J Phys Chem C 112:11722-11728

75. Guo YR, Yu FD, Fang GZ, Pan QJ (2013) J Alloys Compd 552:70-75

76. Nunez-Flores R, Gimenez B, Fernandez-Martın F, Lopez-Caballero M, Montero M, Gomez-Guillen M (2011) Food Hydrocoll 27:60-71

77. Miao TT, Guo YR, Pan QJ (2013) J Nanopart Res 15:1725

78. Liu A, Honma I, Ichihara M, Zhou H (2006) Nanotechnology 17:2845-2849

79. Liu Y, Gao L, Sun J (2007) J Phys Chem C 111:1223-1229

80. Kai D, Tan MJ, Chee PL, Chua YK, Yap YL, Loh XJ (2016) Green Chem 18:1175-1200

81. Wang X, Zhang Y, Hao C, Feng F, Yin H, Si N (2014) Ind Eng Chem Res 53:6585-6592

82. Zhang X, Chen YL, Liu RS, Tsai DP (2013) Rep Prog Phys 76:046401

83. Chaturvedi S, Dave PN (2012) Mater Sci Forum 734:273-294

84. Jiang L, Wang Y, Feng C (2012) Procedia Eng 45:993-997

85. Colmenares JC, Varma RS, Nair V (2017) Chem Soc Rev 46:6675-6686

86. Colmenares JC, Kuna E (2017) Molecules 22:790

87. Song L, Guo C, Li T, Zhang S (2017) Ceram Int 43:7901-7907

88. Ghosh T, Oh WC (2012) Asian J Chem 24:5419-5423

89. Schneider M, Widberger M, Duff DG, Mallant T, Maciejewsks M, Baiker A (1995) Scientific bases for the preparation of heterogeneous catalyst, Preparation of Catalyst, vol 6. Elsevier, Amsterdam

90. Singh AK, Nakate UT (2013) J Nanopart 2013:1-7

91. Fang R, Cheng XS, Xu XR (2010) Bioresour Technol 101:7323-7329

92. Uddin MT, Nicolas Y, Olivier C, Toupance T, Servant L, Muller MM, Kleebe HJ, Ziegler J, Jaegermann W (2012) Inorg Chem 51:7764-7773

93. Xiaohong W, Wenjing X, Chen H, Pengfei Z, Xiaoqi F, Naicha S (2013) Acta Metall Sin 49:1098-1104

94. Akir A, Hamdi A, Addad Y, Coffinier R, Boukherroub ADO (2017) Appl Surf Sci 400:461-470

95. Ferrizz RM, Gorte RJ, Vohs JM (2002) Catal Lett 82:123-129

96. Li X, Guo W, Huang H, Chen T, Zhang M, Wang Y (2014) J Nanosci Nanotechnol 5:3428-3432

97. Umadevi M, Christy AJ (2013) Spectrochim Acta A 109:133-137

98. Barreca D, Fornasiero P, Gasparotto A, Gombac V, Maccato C, Montini T, Tondello E (2009) ChemSusChem 2:230-233

99. Editorial (2012) Nat Photon 6:129

100. Mei A, Li X, Liu L, Ku Z, Liu T, Rong Y, Xu M, Hu M, Chen J, Yang Y, Han H, Graetzel M (2014) Science 345:295-298

101. Lim KG, Kim HB, Jeong J, Kim H, Kim JY, Lee TW (2014) Adv Mater 26:6461-6466

102. Palumbiny CM, Liu F, Russell TP, Hexemer A, Wang C, Muller-Buschbaum P (2015) Adv Mater 27:3391-3397 
103. Wu Y, Wang J, Qiu X, Yang R, Lou H, Bao X, Li Y (2016) ACS Appl Mater Interfaces 8:12377-12383

104. Qian Y, Qiu X, Zhu S (2015) Green Chem 17:320-324

105. Li Y, Hong N (2015) J Mater Chem A 3:21537-21544

106. Ouyang J (2013) Displays 34:423-436

107. Srinivasan MV, Ito M, Kumar P, Abhirami K, Tsuda N, Yamada J, Shin PK, Ochiai S (2015) Ind Eng Chem Res 54:181-187

108. Guo S, Cao BY, Wang WJ, Moulin JF, Muller- Buschbaum P (2015) ACS Appl Mater Interfaces 7:4641-4649

109. Hong N, Qiu X, Deng W, He Z, Li Y (2015) RSC Adv 5:90913-90921

110. Wang J, Jin C, Sun Q, Zhang Q (2017) J Alloys Compd. 702:418-426

111. Diebold VB, Cowan WF, Walsh JK (1978) Solvent pulping process, US patent 4,100,016

112. Strassberger Z, Tanase S, Rothenberg G (2014) RSC Adv 4:25310-25318

113. Feng F, Hao C, Zhang H, Xie W, Wang X, Zhao Y (2015) J Mater Sci Mater Electron 26:6704-6711

114. Morsella M, Alessandro N, Lanterna AE, Scaiano JC (2016) ACS Omega 1:464-469 